\title{
Cross-talk between $i$ NKT cells and monocytes triggers an atheroprotective immune response in SLE patients with asymptomatic plaque\#
}

Short title: iNKT cells oppose pre-clinical plaque development Authors: Edward Smith ${ }^{1 \dagger}$, Sara Croca $^{1 \dagger}$, Kirsty Waddington ${ }^{1,2 \dagger}$, Reecha Sofat ${ }^{2}$, Maura Griffin ${ }^{3}$, Andrew Nicolaides ${ }^{3,4,5}$, David A Isenberg ${ }^{1}$, Ines Pineda Torra ${ }^{2}$, Anisur Rahman ${ }^{1}$, Elizabeth C Jury $^{1 *}$

Affiliations: ${ }^{1}$ Centre for Rheumatology Research, Department of Medicine, University College London, Rayne Building, London W1CE 6JF

${ }^{2}$ Centre for Clinical Pharmacology, Department of Medicine, University College London, Rayne Building, London W1CE 6JF

${ }^{3}$ Vascular Noninvasive Diagnostic Centre, London, UK

${ }^{4}$ Department of Vascular Surgery, Imperial College, London, UK

${ }^{5}$ Department of Vascular Surgery, Nicosia Medical School, University of Nicosia, Cyprus †These authors share first authorship.

\#"This manuscript has been accepted for publication in Science Immunology. This version has not undergone final editing. Please refer to the complete version of record at www.scienceimmunology.org. The manuscript may not be reproduced or used in any manner that does not fall within the fair use provisions of the Copyright Act without the prior, written permission of AAAS."

* Corresponding Author: Elizabeth Jury PhD 
Centre for Rheumatology Research, University College London

Rayne Building, 5 University Street, London W1CE 6JF, UK

Telephone: 44(0)20 3108 2154; Fax: 44(0)20 3108 2152. E-mail: e.jury@ucl.ac.uk

One Sentence Summary: Altered activation of invariant Natural Killer T-cells in patients with pre-clinical plaque protect against atherogenesis via IL-4-mediated polarization of antiinflammatory M2-monocytes. 


\begin{abstract}
Accelerated atherosclerosis is a complication of the autoimmune rheumatic disease systemic lupus erythematosus (SLE). We questioned the role played by invariant Natural Killer T-(iNKT) cells in this process, since they are defective in autoimmunity but also promote atherosclerosis in response to CD1d-mediated lipid-antigen presentation. iNKT-cells from SLE patients with asymptomatic plaque (SLE-P) had increased proliferation and IL-4 production compared to SLE patients with no plaque. The anti-inflammatory iNKT-cell phenotype was associated with dyslipidaemia and was driven by altered monocyte phospholipid expression and CD1d-mediated cross-talk between iNKT-cells and monocytes but not B-cells. Healthy iNKT-cells differentiated in the presence of healthy monocytes and SLE-P serum polarized macrophages towards an antiinflammatory M2-phenotype. Conversely, patients with clinical cardiovascular disease had unresponsive iNKT-cells and increased pro-inflammatory monocytes. $i$ NKT-cell function could link immune responses, lipids and cardiovascular disease in SLE patients and, together with serum lipid taxonomy help predict pre-clinical atherosclerosis in SLE patients.
\end{abstract}




\section{ABBREVIATIONS}

$\alpha$-GalCer, $\alpha$-galactosylceramide; APC, antigen presenting cells; CTB, cholera-toxin B; CVD, cardiovascular disease; GSM, Grey Scale Median; HDL, high density lipoprotein; $i$ NKT cells, IDL intermediate density lipoprotein; IMT, intima-media thickness; invariant Natural Killer T cells; iTCR, invariant T cell receptor; LDL, low density lipoprotein; PB, peripheral blood; PBMC, peripheral blood mononuclear cells; PD-1, Programmed cell death protein 1; PPBP, Proplatelet basic protein; STAT-1, Signal transducer and activator of transcription 1; SLE, systemic lupus erythematosus; SLE-P, SLE patients with plaque; SLE-NP, SLE patients without plaque; SLE-CV, SLE patients with cardiovascular disease; VLDL, very low density lipoprotein; 


\section{INTRODUCTION}

Atherosclerosis is a chronic inflammatory disease of the large arteries, characterized by defects in lipid homeostasis. Oxidized lipid antigens within atherosclerotic plaques contribute to disease progression through macrophage differentiation, lipid-antigen presentation and activation of $\mathrm{T}$ cell responses. Patients with systemic lupus erythematosus (SLE) have an increased risk of atherosclerosis compared to the general population with female patients aged 35-44 years being over 50 times more likely to experience a cardiovascular event compared to age-matched female controls (1). Whilst traditional cardiovascular risk factors (including smoking and hypertension) are common in SLE patients (2), they do not account for the increased cardiovascular risk which may be due to persistent inflammation and immune cell dysfunction (3). Dyslipidemia is a conventional risk factor for cardiovascular disease (CVD), but lipids also have potent effects on the immune system. SLE patients have multiple lipid defects including dyslipidemia (3) and altered plasma membrane glycosphingolipid profiles that contribute to abnormal immune cell function $(4,5)$.

Invariant Natural Killer $\mathrm{T}(i \mathrm{NKT})$ cells constitute less than $0.1 \%$ of peripheral blood mononuclear cells (PBMC) and are identified by expression of the V $224 \mathrm{~J} \alpha 18$ invariant $\mathrm{T}$ cell receptor ( $i \mathrm{TCR}$ ) recognizing glycolipid antigen presented via CD1d on antigen presenting cells (APC). $i$ NKT cells mediate a balance between immune activation and tolerance through proliferation and rapid release of both pro- and anti-inflammatory cytokines, resulting in immune cell transactivation and modulation (6). They are implicated in the pathogenesis of many diseases including autoimmunity, cancer, atherosclerosis and allergy (7). 
SLE patients have reduced $i$ NKT cell number and defective function, supporting a protective role for $i$ NKT cells in autoimmunity. Functional defects, whereby $i$ NKT cells fail to proliferate upon stimulation with the sponge-derived $i$ NKT cell agonist $\alpha$-galactosylceramide ( $\alpha$-GalCer) have been attributed to defective CD1d-mediated lipid-antigen presentation in SLE patients $(8,9)$. While several observations support a role for $i$ NKT cells in promoting atherogenesis (10-12), $i$ NKT cells may play a regulatory role during its early stages by promoting atherosclerosis resolution via increased IL-10 production (13). Consequentially, the role of $i$ NKT cells in human atherogenesis remains unclear.

Understanding the progression of subclinical atherosclerotic plaque is important clinically for long-term CVD outcomes in SLE patients (14). We investigated the role of $i \mathrm{NKT}$ cells in the development of subclinical atherosclerosis in 100 patients with SLE who had no previous history of CVD using vascular ultrasound to quantify the presence of plaque and its composition. In our SLE patient cohort, $36 \%$ had subclinical plaque, supporting previous studies (15). SLE patients with pre-clinical plaque (SLE-P) had a distinct anti-inflammatory $i$ NKT cell profile characterized by increased activation and IL-4 production which correlated with serum lipid expression levels and altered lipoprotein composition. Crucially $i$ NKT cells differentiated in the presence of serum from SLE-P patients induced the polarization of M2-like macrophages in vitro. This protective $i$ NKT cell phenotype was lost in SLE patients who had a cardiovascular event. The results support an athero-protective role for $i$ NKT cells driven by serum lipids during the early stages of atherosclerosis which was lost or overwhelmed during the development of clinical atherosclerosis. Furthermore, differences in serum lipid taxonomy were sufficient to cluster 
patients with and without pre-clinical plaque and together with $i$ NKT cell phenotype could be used to predict atherosclerosis development in SLE patients. 


\section{RESULTS}

\section{A distinct $i$ NKT cell phenotype in SLE patients with pre-clinical plaque}

We examined peripheral blood (PB) $i$ NKT cell frequency and function in SLE patients assessed for pre-clinical atherosclerosis by carotid and femoral artery ultrasound scan (Supplementary Methods). SLE patients with asymptomatic plaques (SLE-P) were older, had longer disease duration and higher mean systolic blood pressure compared to SLE patients without plaque (SLE-NP), however, no association between plaque presence and current or persistent disease activity, medication or anti-dsDNA antibody or C3 levels were seen (table S1). Healthy donors (HC, who were not scanned) were selected based on their gender, age, smoking status and cardiovascular history which indicated that they were unlikely to have plaque (table S1). PB $i$ NKT cell frequency was significantly reduced in SLE-NP patients compared to HCs confirming previous observations $(8,9)$ however, this reduction was lost in SLE-P patients (Fig. 1A, 1B and fig. S1A for gating strategy). This discrepancy was not explained by associations with age, disease duration, systolic blood pressure, treatment (9) or other clinical features and was stable over time (fig. S1B-E and table S1). $i$ NKT cells from SLE-P patients also preferentially produced IL-4 (Fig. 1C and D) and had a significantly lower IFN-צ: IL-4 production ratio (Fig. 1E) compared to SLE-NP patients and HC. This was corroborated by an increased expression of Th2 transcription factor GATA-3 (GATA-binding protein 3) compared to Th1-associated T-Bet (T-box transcription factor) (Fig. 1F and G).

Increased $i$ NKT cell frequency and IL-4 production in SLE-P compared to SLE-NP patients was associated with a switch towards CD4 positivity, a significant decrease in double negative (CD4CD8-) $i$ NKT cells (fig. S2A and B), significantly elevated CD69 and reduced CD161 (NK marker) and PD-1 (Programmed cell death protein 1) expression levels (fig. S2C and D). This 
phenotype was not recapitulated in conventional $\mathrm{CD} 3^{+} \mathrm{CD} 4^{+}$or $\mathrm{CD} 3^{+} \mathrm{CD} 8^{+} \mathrm{T}$ cells (Fig. S2E and S2F).

Increased $i$ NKT cell activation in SLE-P patients was corroborated in vitro by testing their proliferative capacity in response to $\alpha$-GalCer (a potent $i$ NKT cell agonist) and IL-2. SLE-P patients had increased expression of cell proliferation marker Ki-67 and increased $i$ NKT cell frequency, similar to the HCs, showing that they had proliferated in response to $\alpha$-GalCer/IL-2 (Fig. 1H-J) and indicating that they had an altered functional potential compared to SLE-NP cells that did not proliferate as shown previously (9). Furthermore, costimulatory molecule ICOS (inducible T-cell co-stimulator), previously associated with anti-inflammatory responses, was significantly elevated in SLE-P compared to SLE-NP $i$ NKT cells, while no differences were seen in the expression of CD40L following $\alpha$-GalCer stimulation (Fig. 1K). Thus $i$ NKT cell frequency and function was altered in SLE patients with sub-clinical atherosclerosis compared to SLE-NP patients.

\section{Dyslipidaemia correlated with $i$ NKT cell phenotype in SLE-P patients}

We reasoned that serum factors could drive differential $i$ NKT cell phenotype and function between SLE-P and SLE-NP patients. To test this we cultured healthy donor PBMCs with serum from SLE-P patients, SLE-NP patients or heterologous HCs. Only serum from SLE-P patients induced increased $i$ NKT cell expansion and IL-4 production similar to the ex vivo $i$ NKT cell phenotype seen in SLE patients with pre-clinical plaque (Fig. 2A-D). This was prevented by the addition of blocking anti-CD1d antibody (Fig. 2E) indicating that lipid antigen presentation was required for the differential $i$ NKT cell activation in SLE-P patients. 
Since no differences in serum cytokine levels were detected between SLE-P and SLE-NP patients (fig. S3A and table S2) we next assessed whether dyslipidaemia, a risk factor for atherosclerosis, was associated with the altered $i$ NKT cell activation in SLE-P patients. Serum lipid composition analyzed using proton nuclear magnetic resonance spectroscopy (16) revealed elevated concentrations of VLDL but not IDL, LDL or HDL particles in SLE-P compared to SLE-NP patients (Fig. 2F and fig. S3B). Furthermore, significant differences were detected in the proportions of free cholesterol, cholesterol esters, phospholipids and triglycerides carried by lipoprotein subclasses (particularly in VLDL lipoproteins) as well as other serum metabolomic components in SLE-P compared to SLE-NP patients (Fig. 2F, fig. S3C and table Sz3). Supervised hierarchical clustering showed that differences in metabolite expression between patients with and without pre-clinical plaque were sufficient for the two patient groups to be segregated (Figure S4). In comparison, serum lipid measures quantified in the clinical laboratory as part of routine patient management were within normal clinical ranges for our hospital. Only triglyceride levels and total cholesterol:HDL ratios were significantly elevated in SLE-P patients compared to SLE-NP patients, consistent with these being risk factors for atherosclerosis development, although no relationship with $i$ NKT cell frequency was detected (Table S34). $i$ NKT cell frequency was inversely correlated with free cholesterol and phospholipid content in VLDL particles in the SLE-P but not the SLE-NP patients (Fig. 2G and table S45) and a strong positive correlation was observed between $i$ NKT-cell IL-4 production and serum lipids including triglycerides, cholesterol:HDL ratio and total fatty acid ratios in SLE-P but not the SLE-NP patients (Fig. 2H and 2I and table S45). Interestingly, serum and isolated serum VLDL/LDL from SLE-NP patients increased phospholipid accumulation in HC monocytes but not B cells compared to serum from SLE-P patients and heterogeneous HCs (Fig. 2J and 2K). Thus, serum 
from SLE-P patients was able to recapitulate the $i$ NKT cell phenotype associated with preclinical atherosclerosis in cells from HCs and this was associated with dyslipidemia.

\section{Monocyte lipid-antigen presentation triggers anti-inflammatory $i$ NKT cell responses in}

\section{SLE-P patients}

The results suggested that changes in CD1d-mediated lipid antigen presentation by APCs could be influencing differential $i$ NKT cell function. Therefore we isolated cellular lipids from purified ex vivo monocytes and B cells from SLE-NP, SLE-P and HCs (Fig. 3A for experimental plan). Initial experiments established that $i$ NKT cells from healthy donors responded more robustly to lipid fraction 5 (F5) containing phospholipids and sphingomyelin regardless of whether lipids were isolated from monocytes or B cells (Fig. 3B). However, only monocyte-F5-lipids isolated from SLE-P patients induced a significant increase in $i$ NKT cell expansion (Fig. 3C and 3D) and a more anti-inflammatory cytokine environment, characterized by increased IL-4, IL-13 and reduced IFN-y in tissue culture supernatants compared to SLE-NP patients or controls (Fig. 3E); responses that were also reversed by the addition of anti-CD1d antibody (Fig. 3F and 3G). Thus the results suggested that F5 lipids presented via monocyte, rather than B cell, CD1d were more effective at inducing $i$ NKT cell activation in SLE-P patients compared to those presented by SLE-NP patients and that this triggered the production of anti-inflammatory and potentially athero-protective cytokines $(17,18)$.

\section{$i$ NKT cells from SLE-P patients support M2 monocyte/macrophage polarization}

Since monocytes are central players in the pathogenesis of atherosclerosis and express high levels of CD1d, we examined their role in $i \mathrm{NKT}$ cell activation in more detail. No significant 
differences in the expression of monocyte CD36, LDL-receptor(R), LOX-1 (oxidized lowdensity lipoprotein receptor-1) and LRP-1 (Low density lipoprotein receptor-related protein-1), receptors that facilitate lipid uptake from the microenvironment or CD1d, were detected between HCs and SLE patients (fig. S5). However, using a combination of monocyte gating strategies we observed that monocytes from SLE-P patients were less inflammatory compared to SLE-NP patients. Pro-inflammatory intermediate monocytes $\left(\mathrm{CD} 14^{++} \mathrm{CD} 16^{+}\right)(19)$ were significantly increased in SLE-NP patients compared to HCs and SLE-P patients (Fig. 4A and 4B). Moreover, using the monocyte phenotyping strategy described by Fadini et al (20) the M1:M2 monocyte ratio was significantly elevated in SLE-NP compared to SLE-P patients and HCs, driven by increased M1-like $\left(\mathrm{CD} 14^{+} \mathrm{CD} 68^{+} \mathrm{CCR} 2^{+}\right)$and reduced M2-like $\left(\mathrm{CD} 14^{+} \mathrm{CD} 206^{+} \mathrm{CX}_{3} \mathrm{CR} 1^{+}\right)$ monocyte frequencies in SLE-NP patients compared to HCs and SLE-P patients (Fig. 4C-F). We investigated whether serum from SLE-P, SLE-NP patients and HCs could influence monocyte/macrophage polarization. Strikingly, serum in the absence of T cells had no effect on in vitro polarization of M2 macrophages/monocytes detected by CD206 (mannose receptor) which is regulated by IL-4 (21) (Fig. 4G and 4H). However, co-culture of purified monocytes and $\mathrm{T}$ cells (containing $i \mathrm{NKT}$ cells) from HCs with SLE-P serum (but not SLE-NP or HC serum) preferentially induced the polarization of $\mathrm{CD} 206^{+} \mathrm{M} 2$ macrophages (Fig. 4I for experimental strategy and 4J). This was associated with concomitant increase in CD206 gene expression and reduced expression of M1-associated STAT-1 (Signal transducer and activator of transcription 1) expression (Fig. 4K).

To establish the role of $i$ NKT cells in driving this process we differentiated $i$ NKT cells with SLE-P and SLE-NP serum then co-cultured the pre-conditioned $i$ NKT cells with human THP-1 macrophages (22) (in order to exclude differences between macrophages derived from healthy 
donor PBMCs). Only $i$ NKT cells exposed to monocytes and SLE-P serum induced upregulation of CD206 and down regulation of STAT-1 genes associated with M2 and M1 macrophage polarization respectively, while no differential effect was observed with expression of other M2 (CD200R) and M1 (PPBP (Pro-platelet basic protein) or CD80) macrophage-associated genes $(23,24)$ (Fig. 4K for experimental strategy, 4L). However, blocking IL-4 using anti-IL-4 blocking antibody increased STAT-1 and CD80 gene expression compared to isotype control but did not significantly influence CD206 expression and no differential effect was observed between the patient groups (Fig. 4N and4O) suggesting that increased M2 monocyte/macrophage polarisation was not exclusively IL-4 mediated.

\section{SLE patients with clinical cardiovascular disease lost their 'anti-inflammatory' $i$ NKT cell profile}

The results indicated that $i$ NKT cells had an athero-protective response in SLE patients with subclinical plaque. Stratification of SLE-P patients according to number of plaque sites, revealed a strong relationship between $i \mathrm{NKT}$ cell phenotype and plaque echolucency, a gauge of plaque stability and lipid content measured by Grey Scale Median (GSM, supplemental methods for description of GSM assessment (25)). In patients with 1-2 plaque sites, more stable and less echolucent plaques (higher GSM score) correlated positively with $i$ NKT cell frequency and $i$ NKT cell-IL-4 production, while no associations were detected in patients with $>3$ plaque sites or between $i \mathrm{NKT}$ cell phenotype and other plaque measures (fig. S6).

To investigate this further in relation to clinical cardiovascular disease we included an additional cohort of SLE patients that had suffered a cardiovascular event (SLE-CV). Table S56 details the SLE-CV patient characteristics; no differences in serum lipid profile were detected between the 
SLE-P and SLE-CV groups or between SLE-P patients with 1-2 vs 3-4 plaque sites (fig.S7A-D). However, SLE-CV patients, had a different $i$ NKT cell phenotype, characterized by low PB frequency, increased CD8 ${ }^{+}$phenotype, reduced CD69 expression and low ex vivo expression of IL-4 and IFN-y compared to SLE-P and SLE-NP patients (Fig. 5A-G). This was associated with increased expression of pro-inflammatory monocytes $\left(\mathrm{CD} 14^{++} \mathrm{CD} 16^{+}\right)$and reduced $\mathrm{M} 2$-like monocyte frequency (Fig. 5H-J). Stratification of SLE-P patients according to number of plaque sites revealed a trend towards reduced $i$ NKT cell frequency and activation in patients with more than three plaque sites similar to patients with clinical CVD (Fig. 5A-J and S7D).

Thus SLE patients with different stages of atherosclerosis development had distinct $i$ NKT cell phenotypes (Fig. 5K). In particular $i$ NKT cells from SLE-CV patients had a 'non-activated' ex vivo phenotype and did not proliferate in response to $\alpha \mathrm{GalCer}$ stimulation (Fig S7E). Hence we suggest a potential mechanism whereby in SLE-P patients anti-inflammatory $i$ NKT cell responses, potentially driven by dyslipidaemia and altered phospholipid-antigen presentation, reflect an attempt to resolve inflammatory processes during early plaque formation. In patients with clinical cardiovascular disease, $i$ NKT cells lost their anti-inflammatory potential and had an 'inactive' phenotype (Fig. 6A-C). 


\section{DISCUSSION}

SLE patients have an increased risk of developing both clinically apparent CVD and subclinical atherosclerotic plaque, however, while dyslipidemia and immune dysfunction have been widely described in patients with SLE, their role in the development of atherosclerosis is not clear. Here we identified a protective role for $i \mathrm{NKT}$ cells in the immune response against early atherosclerosis. Three key observations supported this conclusion; firstly SLE-P patients had an $i$ NKT cell phenotype characterized by increased activation and IL-4 production; secondly, SLEP patients had an altered serum lipid profile, in particular altered lipoprotein composition that correlated with the anti-inflammatory $i$ NKT cell phenotype and thirdly, iNKT cells differentiated in the presence of SLE-P serum induced the polarization of atheroprotective M2 monocytes/macrophages.

The role of $i$ NKT cells in human disease remains elusive; $i$ NKT cells have a reduced PB frequency in both autoimmunity, including $\operatorname{SLE}(8,9)$, and atherosclerosis $(26)$, potentially due to $i$ NKT cell migration to inflamed tissues (27). Beyond this little detailed information about $i$ NKT cell phenotype in patients with atherosclerosis exists. We revealed that SLE-P patients had increased $\mathrm{CD} 4{ }^{+} i \mathrm{NKT}$ cell number, IL-4 production and GATA-3 expression compared to SLENP patients; characteristic of NKT2 cells, a functional $i$ NKT cell subset with anti-inflammatory properties (28). $\mathrm{CD}^{+} i \mathrm{NKT}$ cells have previously been isolated from human plaque tissue (26) and associated with Th2 responses in healthy donors (29) and cancer patients (30). However, there is no consensus on the role played by $i \mathrm{NKT}$ cells during preclinical atherosclerosis since they promote fatty streak formation in LDLR-/- mice (31), but have an athero-protective role during the early stages of plaque development via increased IL-10 production (13). We found 
that patients with clinical CVD (SLE-CV) lost the potentially protective NKT2-like phenotype and had reduced IL-4 and IFN- $\gamma$ production similar to $i \mathrm{NKT}$ cells from ApoE ${ }^{-/-}$mice with advanced plaques (11).

Our findings support marked $i$ NKT cell phenotypic heterogeneity during human health and disease which could be driven by factors including serum lipids or cytokines since $i$ NKT cells can be activated by both self and foreign antigens via the $i \mathrm{TCR}$ and/or or by $i \mathrm{TCR}$-independent mechanisms via cytokine stimulation, notably IL-12 and IL-18 released by APCs(32). Standard serum lipid assessments were within normal ranges for all patients however, the metabolomic analysis revealed a significant alteration in lipoprotein particle concentration and lipid composition between SLE-P and SLE-NP patients, however, we did not detect differences in the levels of IL-12 and IL-18bp (essential for IL-18 function) which are known to promote IFN-ymediated iNKT1 responses (33). Nevertheless, changes in the balance between $i$ TCR and cytokine signals could play a role in the altered $i$ NKT cell IFN-y:IL4 ratio observed in SLE-P compared to SLE-NP patients and it would be interesting to investigate further whether the trend towards reduced IL-12 levels in the SLE-P patients contributes to this process (32). Differences in lipoproteins are known to predict subclinical atherosclerosis in the general population (34). However, there is little information on lipoprotein subclasses in SLE patients despite reports of defects in serum metabolite and lipid content (35) and reduced capacity of serum to sustain cholesterol efflux from THP-1 macrophages (36). We are therefore the first to identify variations in serum lipoproteins between SLE patients with and without pre-clinical plaque suggesting that more detailed analysis of lipoprotein taxonomy could help to predict cardiovascular risk in SLE patients. 
Although the exact mechanism linking serum lipids and $i$ NKT cell activation in SLE-P patients remains to be determined, we have identified a potential role for phospholipids in driving this anti-inflammatory $i$ NKT cell response in SLE patients. No significant differences in the expression of lipoprotein or scavenger receptors were detected on monocytes from SLE patients and healthy donors potentially ruling out changes in the rate of lipid uptake. We identified differences in lipoprotein expression and lipid composition between the SLE-NP and SLE-P patient groups and it is tempting to speculate a link between VLDL-lipid content and the significant expansion of anti-inflammatory $i$ NKT cells. In particular, VLDL from SLE-P serum contained increased phospholipids, which are known to activate $i$ NKT cells (37). However, healthy PBMC culture with VLDL purified from SLE-P patients did not influence $i$ NKT cell phenotype therefore the relevance of changes in VLDL lipid composition deserve further investigation. Importantly, VLDL heterogeneity is associated with early onset atherosclerosis in autoimmunity (38) and enzymes involved in lipid processing and presentation including lipoprotein lipase and the adipokine resistin, which have altered expression levels in SLE patients $(39,40)$. Our results support previous observations that VLDL influences lipid accumulation in monocytes (41), which could have further implications on CD1d-mediated lipid antigen presentation to $i \mathrm{NKT}$ cells.

Despite extensive work investigating monocyte/macrophage subsets in vitro and in animal models of atherosclerosis, evidence of their patho-physiological relevance in a clinical setting remains uncertain (21). Previous studies on human plaques demonstrate the presence of both M1 and M2 macrophages during developing atherosclerosis with a role for M2 macrophages during early stages $(24,42)$. Using the monocyte phenotype described by Fadini et al (20),we show higher frequencies of M2-like monocytes in PB from SLE-P patients compared to both SLE-NP patients 
and SLE-CV patients. This was in contrast to Fadini et al who reported increased M1-like monocytes and decreased M2-like monocytes in patients with Familial and Non-familial hypercholesterolemia with asymptomatic plaque (but no history of autoimmunity). However, the severe dyslipidemia in these patients was not seen in the SLE patients from our study, whose serum lipids were all within the standard normal range used in clinical practice.

The M1:M2-like monocyte ratio was increased in SLE-P compared to SLE-NP patients driven by increased M1 and reduced M2-like monocyte frequencies in SLE-NP patients. SLE-P serum was able to induce M2-like macrophage polarization but only in the presence of $i$ NKT cells. This finding corroborates previous observations in experimental autoimmune encephalomyelitis, where $i$ NKT cell deficient mice have fewer M2 macrophages and worse disease (43). Similarly, in a mouse model of obesity $\alpha$-GalCer treatment significantly increased both $i$ NKT cell numbers and M2 macrophage polarisation mediated by in part by IL-4 (44). We observed increased CD206 and reduced STAT-1 gene expression in adherent healthy macrophages from PBMC cultures with SLE-P serum and in THP-1 macrophages upon co-culture with $i$ NKT cells preconditioned using SLE-P serum. Although CD206 gene expression is known to be upregulated in response to IL-4 $(23,45)$, blocking IL-4 increased M1 gene expression (STAT-1 and CD80) but had no effect on CD206. This suggests that $i$ KKT cell-monocyte/macrophage cross-talk and the promotion of M2 macrophage differentiation is a more complex mechanism potentially involving other cytokines including IL-13, which was increased in response to F5 lipid stimulation (Fig. 3E), and transactivation of other cell types $(18,44)$. Conversely, during the later stages of atherosclerosis (in SLE-CV patients and in SLE-P patients with 3-4 plaque sites), this protective response appeared to be reduced or overwhelmed leading to $i \mathrm{NKT}$ cell 
exhaustion, reduced anti-inflammatory M2-like monocytes and increased pro-inflammatory 'intermediate' monocyte populations, in line with studies showing a predominance of M1 macrophages in more advanced rupture prone lesions (46-48) where the immune balance shifts from tissue repair towards chronic inflammation.

A limitation of this study is the lack of ultrasound scan data for HCs and SLE-CV patients. However, follow up scans of SLE-NP and SLE-P patients and reassessment of their cardiovascular disease history and metabolomics status will enable more detailed evaluation of how $i \mathrm{NKT}$ cells either protect against or promote atherosclerosis at different stages of the disease in SLE patients. Furthermore, it remains to be determined whether changes in serum lipids in SLE-P patients are potent enough to support a protective $i$ NKT-cell mediated immune response in vivo, whether this is specific to plaque sites or whether the protective $i$ NKT cell phenotype is common to patients with atherosclerosis in other autoimmune diseases or atherogenesis in the absence of autoimmunity.

In summary, we show that $i$ NKT cells could play a key role in linking the immune system, lipids and CVD in patients with SLE. This supports the development of new diagnostic and therapeutic targets for patients at increased cardiovascular risk. Close monitoring of iNKT cell phenotype and/or serum lipid levels, since serum lipoprotein taxonomy was able to cluster patients with and without pre-clinical plaque, could represent a novel 'barcode' to predict atherosclerosis development in SLE patients and in other at risk patient groups. 


\section{MATERIALS AND METHODS}

\section{Study Design}

SLE patients have an increased risk of developing clinically apparent CVD and subclinical atherosclerotic plaque, detectable by vascular ultrasound. Although dyslipidemia and immune dysfunction are widely described in SLE, their role in atherosclerosis is unclear. We propose that $i$ NKT cells, responding to CD1d-lipid antigens presented by APCs, play a key role in linking the immune system, lipids and CVD in SLE patients. Vascular ultrasound on 100 patients with SLE but no history of CVD showed $36 \%$ had pre-clinical plaque. The study had research ethics committee (06/Q0505/79) approval. Informed consent was obtained from all participants. Patient samples (SLE-P, SLE-NP and HC) were randomly assigned to experimental groups. No statistical methods were used to predetermine sample size which was chosen using records of variance in past experiments.

In controlled laboratory experiments PBMCs and serum from SLE-NP, SLE-P and HCs were used to assess $i \mathrm{NKT}$ cell and CD1 $\mathrm{d}^{+}$-APCs phenotype and function by flow cytometry which was performed routinely during the 3 year study. For comparison SLE patients and who had suffered a cardiovascular event were recruited subsequent to collection of the original cohort. Serum metabolomics was performed on all scanned patients by nuclear magnetic resonance and lipids were purified from APCs by chloroform/methanol isolation. Gene expression was analyzed using qPCR. In vitro cell culture experiments were performed on at least 3 separate occasions with different HCs and SLE patient cells and serum. Data was grouped (SLE-P, SLENP and HC) for analysis. Details of exact sample numbers for each experiment are detailed in the figure legends. 


\section{Patients and controls}

Carotid and femoral ultrasound scans were performed on 100 patients who met America College of Rheumatology criteria for SLE (49) and had no previous history of CVD. Absence of CVD (defined as coronary artery disease, stroke or myocardial infarction with confirmatory evidence from blood tests and/or imaging) was confirmed by analysis of medical records. See supplementary methods for details of scanning. Eleven SLE patients who had suffered cardiovascular disease events (SLE-CV) and 50 HCs were recruited but were not scanned because ethical approval was not available. Clinical, demographic, serological, therapy and disease activity characteristics for SLE-P and SLE-NP patients, HCs (table S1) and SLE-CV patients (table S5) are shown.

\section{Cell culture}

PBMCs $\left(5 \times 10^{6}\right)$ were cultured for 0-7 days (ds) in complete medium (RPMI 1640, 10-50\% pooled human sera (PHS), 1\% penicillin/streptomycin (Sigma)). For $\alpha$-GalCer-induced iNKT cell expansion, $100 \mathrm{ng} / \mathrm{ml} \alpha$-GalCer (Alexis Biochemicals) and 200IU/ml IL-2 (R\&D Systems) was used. In some cases $5 \times 10^{6}$ PBMC were cultured for $7 \mathrm{ds}$, in $50 \%$ serum from HCs or SLE patients \pm anti-CD1d (10 $\mathrm{g} / \mathrm{ml})$ (BD Pharmingen) or \pm anti-IL-4 (InvivoGen) or appropriate isotype controls where indicated. Alternatively, PBMCs were cultured with lipid fractions isolated from HC, SLE-NP or SLE-P B cells or monocytes for 7ds (1:100 in complete medium, IL-2, \pm anti-CD1d/isotype as indicated).

Monocyte/macrophage polarization: CD14+monocytes were negatively isolated and CD3+T cells (including iNKT cells) were positively isolated using magnetic beads (EasySep; Stemcell Technologies) or THP-1 cells were used as APCs. Co-cultures had 1monocyte: $2 \mathrm{~T}$ cells with 
minimum $5 \times 10^{6}$ cells/well. Cell culture supernatants were collected and analysed by Cytometric Bead Array (CBA) (BD) according to manufacturer's instructions.

THP-1 co-culture: THP-1 cells (human monocytic cell line), 400,000 cells/mL in 6-well plates were cultured for $72 \mathrm{hs}$ in complete medium, $20 \mathrm{ug} / \mathrm{mL}$ gentamycin and $5 \mathrm{ng} / \mathrm{mL}$ phorbol-12myrisate 13-acetate (PMA) (Sigma), washed with PBS and rested for 24hs in complete medium. PBMCs from HCs were incubated for 4ds with serum from heterologous HCs, SLE-NP or SLE$\mathrm{P}$ patients to differentiate $i \mathrm{NKT}$ cells. $\mathrm{CD}^{+} \mathrm{T}$ cells (including $i \mathrm{NKT}$ cells) were positively selected using the EasySep magnetic isolation and $1.5 \times 10^{6}$ cells were co-cultured with THP-1 macrophages. After 40hs, medium and T cells were removed, THP-1 cells were washed once with PBS and lysed in TRIzol (Invitrogen) for RNA extraction.

\section{Flow Cytometry}

iNKT cell and monocyte phenotyping: $5 \times 10^{6}$ PBMCs were surface stained in cold FACS buffer (PBS; $1 \% \mathrm{FCS} ; 0.01 \% \mathrm{NaN}_{3} ; 0.5 \%$ EDTA), using the following antibodies (from Biolegend unless indicated): $i$ TCR-PE(6B11) (BD Bioscience) and CD3-APC/efluor780 (eBioscience) for $i$ NKT cells, with subsets CD4-BV605 and CD8-BV705 and CD25-alexafluor700, CD69-BV785 and PD-1-PE/Cy7, CD161-BV421, and CCR6-FITC (eBioscience) and for monocytes CD14efluor450, CD16-APC, CD68-PE/Cy7, CX3CR1-FITC, CCR2-PerCP/Cy5.5, and CD206-PE. Cells were incubated at $4{ }^{\circ} \mathrm{C}$ for 20 minutes, washed, fixed with $2 \%$ paraformaldehyde and resuspended in FACS buffer for analysis.

iNKT cell intracellular cytokine staining: PBMCs were cultured for 4 hours with 50ng/ml PMA, 250ng/ml ionomycin and 1:1000 Golgiplug (BD Bioscience) then washed and surface stained for $i \mathrm{NKT}$ cells, fixed, permeabilised (eBiosciences) and stained intracellularly with IFN $\gamma$-efluor450 
(eBioscience) and IL-4-APC. $i$ NKT cell proliferation was assessed by intracellular staining for Ki-67-PE (BD Bioscience) or transcription factors T-bet-PerCP/Cy5.5 and GATA-3-alexa647. Flow cytometry acquisition using a BD LSR II flow cytometer acquiring $1-5 \times 10^{6}$ cells per sample, data analyzed using FlowJo version vX (TreeStar).

\section{Phospholipid detection}

Phospholipids were detected using HCS LipidTOX ${ }^{\mathrm{TM}}$ Phospholipidosis Detection Reagent (Invitrogen) according to manufacturer's instructions and flow cytometry.

\section{Lipid isolation}

Cellular lipids isolated from $1 \times 10^{7}$ FACS-sorted and PBS-washed B cells and monocytes by chloroform:methanol extraction (v/v) (50) and fractionation using Amino Propyl columns(Sigma). Nitrogen-dried lipids reconstituted in $500 \mu$ l chloroform were added to columns and eluted accordingly: F1: $2 \mathrm{ml}$ diethyl-ether; F2: $1.6 \mathrm{ml} \mathrm{CHCl3:MeOH} \mathrm{(23:1} \mathrm{v/v);} \mathrm{F3:} 1.8 \mathrm{ml}$ di-isopropylether:acetic acid (98:4 v/v); F4: 2 ml acetone:MeOH (9:1.2 v/v); F5: 2 ml CHCl3:MeOH (2:1 v/v); F6: $2 \mathrm{ml} 0.2 \mathrm{M} \mathrm{CH} 3 \mathrm{COONH} 4$ in $\mathrm{MeOH}$ and $2 \mathrm{ml} \mathrm{dH}{ }_{2} \mathrm{O}$. Fractions were dried under nitrogen, stored at $-80^{\circ} \mathrm{C}$ and resuspended in $50 \mu 1 \mathrm{DMSO}$ prior to cell culture. LDL/VLDL purification kit (Cell Biolabs) was performed according to manufacturer's instructions followed by dialysis in PBS (Pierce) and protein quantification using BCA assay (Pierce).

\section{Metabolomics}


Serum metabolomics analysis was performed by Brainshake (Prof Ala-Korpela, University of Eastern Finland) using a biomarker analysis platform (51). Metabolite quantification was by proton nuclear magnetic resonance (NMR) using two spectral windows LIPO and LMWV giving lipoprotein subclass distribution and low molecular weight metabolites. Models were crossvalidated against NMR-independent lipoprotein and lipid data, and verified to lie within a 10\% limit of the training data set.

\section{qPCR}

RNA extraction and cDNA synthesis: Cells were lysed in TRIzol. RNA extraction used RNeasy Micro Kits (Qiagen) and quantified using Nanodrop Spectrophotometer. All 260/280 and 260/230 ratios were >1.9. cDNA from 1000ng RNA using AffinityScript QPCR cDNA Synthesis Kit (Agilent Technologies). qPCR performed using Stratagene Mx3005P qPCR system and Brilliant III SYBR Green Mastermix (Agilent Technologies). Intron spanning or flanking primer pairs (Sigma Aldrich) for CD206, CD200R, STAT-1, CD80 and PPBP designed using Primer-3 and BLAST search performed to ensure specificity. Primers were validated and used at $100 \mathrm{nM}$

\section{Statistics}

Values expressed as absolute mean \pm SEM. Analysis performed using GraphPad Prism (GraphPad Software) using 2-tailed Student's $t$ test, paired Student's $t$ test, One-way ANOVA and Tukeys multiple comparison post T- tests or Pearson's correlation as specified. $P=<0.05$ were considered significant. Normal distribution tested using Kolmogorov-Smirnov test. 


\section{LIST OF SUPPLEMENTARY MATERIALS}

Supplementary Materials and Methods

Fig. S1: Analysis of iNKT cell phenotype in SLE patients and HCs

Fig. S2. $i$ NKT cells from SLE-P patients had an activated phenotype compared to SLE-NP patients and healthy donors

Fig. S3. Serum cytokine and metabolite expression levels in SLE patients with and without plaque

Fig. S4: Hierarchical clustering of metabolites with most significant differences between SLENP and SLE-P patients

Fig. S5: Monocyte/macrophage phenotype in SLE-P, SLE-NP patients and healthy donors Fig. S6: $i$ NKT cell frequency and IL4 production correlates with plaque stability measured by Grey Scale Median (GSM)

Fig S7: Comparison of serum lipid profiles in SLE-P and SLE-CV patients.

Table S1: SLE patient and Healthy donor characteristics

Table S2: Plasma cytokine levels measured by proteomic analysis in in SLE patients with preclinical plaque compared to those without plaque.

Table S3: Serum metabolites significantly altered in SLE patients with pre-clinical plaque compared to those without plaque

Table S4: SLE patient serum lipids and biomarkers

Table S5: Correlation of serum metabolites with $i$ NKT cell frequency and IL-4 production in SLE-P and SLE-NP patients

Table S6: SLE cardiovascular event (SLE-CV) patient clinical characteristics 


\section{REFERENCES AND NOTES:}

1. Manzi S, Meilahn EN, Rairie JE, Conte CG, Medsger TA, Jansen-McWilliams L, D'Agostino RB, and Kuller LH. Age-specific Incidence Rates of Myocardial Infarction and Angina in Women with Systemic Lupus Erythematosus: Comparison with the Framingham Study. American Journal of Epidemiology. 1997;145(5):408-15.

2. Urowitz MB, Gladman D, Ibanez D, Bae SC, Sanchez-Guerrero J, Gordon C, Clarke A, Bernatsky S, Fortin PR, Hanly JG, et al. Atherosclerotic vascular events in a multinational inception cohort of systemic lupus erythematosus. Arthritis Care Res (Hoboken). 2010;62(6):881-7.

3. Hahn BH, Grossman J, Chen W, and McMahon M. The pathogenesis of atherosclerosis in autoimmune rheumatic diseases: Roles of inflammation and dyslipidemia. Journal of Autoimmunity. 2007;28(2-3):6975 .

4. Jury EC, Kabouridis PS, Flores-Borja F, Mageed RA, and Isenberg DA. Altered lipid raft-associated signaling and ganglioside expression in T lymphocytes from patients with systemic lupus erythematosus. The Journal of Clinical Investigation. 2004;113(8):1176-87.

5. McDonald G, Deepak S, Miguel L, Hall CJ, Isenberg DA, Magee AI, Butters T, and Jury EC. Normalizing glycosphingolipids restores function in CD4+ T cells from lupus patients. The Journal of Clinical Investigation. 2014;124(2):712-24.

6. Godfrey DI, MacDonald HR, Kronenberg M, Smyth MJ, and Kaer LV. NKT cells: what's in a name? Nat Rev Immunol. 2004;4(3):231-7.

7. Berzins SP, Smyth MJ, and Baxter AG. Presumed guilty: natural killer T cell defects and human disease. Nat Rev Immunol. 2011;11(2):131-42.

8. Cho Y-N, Kee S-J, Lee S-J, Seo S-R, Kim T-J, Lee S-S, Kim M-S, Lee W-W, Yoo D-H, Kim N, et al. Numerical and functional deficiencies of natural killer T cells in systemic lupus erythematosus: their deficiency related to disease activity. Rheumatology. 2011;50(6):1054-63.

9. Bosma A, Abdel-Gadir A, Isenberg DA, Jury EC, and Mauri C. Lipid-antigen presentation by CD1d(+) B cells is essential for the maintenance of invariant natural killer T cells. Immunity. 2012;36(3):477-90.

10. Melián A, Geng Y-J, Sukhova GK, Libby P, and Porcelli SA. CD1 Expression in Human Atherosclerosis: A Potential Mechanism for T Cell Activation by Foam Cells. The American Journal of Pathology. 1999;155(3):775-86.

11. Nakai Y, Iwabuchi K, Fujii S, Ishimori N, Dashtsoodol N, Watano K, Mishima T, Iwabuchi C, Tanaka S, Bezbradica JS, et al. Natural killer T cells accelerate atherogenesis in mice. Blood. 2004;104(7):2051-9.

12. Tupin E, Nicoletti A, Elhage R, Rudling M, Ljunggren H-G, Hansson GK, and Berne GP. CD1d-dependent Activation of NKT Cells Aggravates Atherosclerosis. The Journal of Experimental Medicine. 2004;199(3):417-22.

13. van Puijvelde GH, van Wanrooij EJ, Hauer AD, de Vos P, van Berkel TJ, and Kuiper J. Effect of natural killer T cell activation on the initiation of atherosclerosis. Thrombosis and haemostasis. 2009;102(2):22330 .

14. Kao AH, Lertratanakul A, Elliott JR, Sattar A, Santelices L, Shaw P, Birru M, Avram Z, Thompson T, Sutton-Tyrrell K, et al. Relation of carotid intima-media thickness and plaque with incident cardiovascular events in women with systemic lupus erythematosus. The American journal of cardiology. 2013;112(7):1025-32.

15. Roman MJ, Shanker BA, Davis A, Lockshin MD, Sammaritano L, Simantov R, Crow MK, Schwartz JE, Paget SA, Devereux RB, et al. Prevalence and correlates of accelerated atherosclerosis in systemic lupus erythematosus. N Engl J Med. 2003;349(25):2399-406.

16. Kettunen J, Tukiainen T, Sarin A-P, Ortega-Alonso A, Tikkanen E, Lyytikainen L-P, Kangas AJ, Soininen P, Wurtz P, Silander K, et al. Genome-wide association study identifies multiple loci influencing human serum metabolite levels. Nat Genet. 2012;44(3):269-76.

17. Ait-Oufella H, Taleb S, Mallat Z, and Tedgui A. Recent Advances on the Role of Cytokines in Atherosclerosis. Arteriosclerosis, Thrombosis, and Vascular Biology. 2011;31(5):969-79.

18. Cardilo-Reis L, Gruber S, Schreier SM, Drechsler M, Papac-Milicevic N, Weber C, Wagner O, Stangl H, Soehnlein O, and Binder CJ. Interleukin-13 protects from atherosclerosis and modulates plaque composition by skewing the macrophage phenotype. EMBO Molecular Medicine. 2012;4(10):1072-86. 
19. Ziegler-Heitbrock L. The CD14+ CD16+ blood monocytes: their role in infection and inflammation. Journal of Leukocyte Biology. 2007;81(3):584-92.

20. Fadini GP, Simoni F, Cappellari R, Vitturi N, Galasso S, Vigili de Kreutzenberg S, Previato L, and Avogaro A. Pro-inflammatory monocyte-macrophage polarization imbalance in human hypercholesterolemia and atherosclerosis. Atherosclerosis. 2014;237(2):805-8.

21. Chistiakov DA, Bobryshev YV, Nikiforov NG, Elizova NV, Sobenin IA, and Orekhov AN. Macrophage phenotypic plasticity in atherosclerosis: The associated features and the peculiarities of the expression of inflammatory genes. International Journal of Cardiology. 2015;184(436-45.

22. Spiller KL, Wrona EA, Romero-Torres S, Pallotta I, Graney PL, Witherel CE, Panicker LM, Feldman RA, Urbanska AM, Santambrogio L, et al. Differential Gene Expression in Human, Murine, and Cell Linederived Macrophages upon Polarization. Experimental Cell Research.

23. Ambarus CA, Krausz S, van Eijk M, Hamann J, Radstake TRDJ, Reedquist KA, Tak PP, and Baeten DLP. Systematic validation of specific phenotypic markers for in vitro polarized human macrophages. Journal of Immunological Methods. 2012;375(1-2):196-206.

24. Brochériou I, Maouche S, Durand H, Braunersreuther V, Le Naour G, Gratchev A, Koskas F, Mach F, Kzhyshkowska J, and Ninio E. Antagonistic regulation of macrophage phenotype by M-CSF and GM-CSF: Implication in atherosclerosis. Atherosclerosis. 2011;214(2):316-24.

25. Nicolaides AN, Kakkos SK, Kyriacou E, Griffin M, Sabetai M, Thomas DJ, Tegos T, Geroulakos G, Labropoulos N, Doré CJ, et al. Asymptomatic internal carotid artery stenosis and cerebrovascular risk stratification. Journal of Vascular Surgery. 2010;52(6):1486-96.e5.

26. Kyriakakis E, Cavallari M, Andert J, Philippova M, Koella C, Bochkov V, Erne P, Wilson SB, Mori L, Biedermann BC, et al. Invariant natural killer T cells: Linking inflammation and neovascularization in human atherosclerosis. European Journal of Immunology. 2010;40(11):3268-79.

27. Hofmann SC, Bosma A, Bruckner-Tuderman L, Vukmanovic-Stejic M, Jury EC, Isenberg DA, and Mauri C. Invariant natural killer $\mathrm{T}$ cells are enriched at the site of cutaneous inflammation in lupus erythematosus. Journal of Dermatological Science. 2013;71(1):22-8.

28. Chandra S, and Kronenberg M. In: Frederick WA ed. Advances in Immunology. Academic Press; 2015:145-201.

29. O'Reilly V, Zeng SG, Bricard G, Atzberger A, Hogan AE, Jackson J, Feighery C, Porcelli SA, and Doherty DG. Distinct and Overlapping Effector Functions of Expanded Human CD $4<\sup >+</$ sup $>$, CD8 $\alpha<$ sup $>+</$ sup $>$ and $\operatorname{CD} 4<$ sup $>-</$ sup $>\operatorname{CD} 8 \alpha<$ sup $>-</$ sup $>$ Invariant Natural Killer T Cells. PLoS ONE. 2011;6(12):e28648.

30. Bricard G, Cesson V, Devevre E, Bouzourene H, Barbey C, Rufer N, Im JS, Alves PM, Martinet O, Halkic $\mathrm{N}$, et al. Enrichment of Human CD4+ V $224 / \mathrm{V} \beta 11$ Invariant NKT Cells in Intrahepatic Malignant Tumors. The Journal of Immunology. 2009;182(8):5140-51.

31. Aslanian AM, Chapman HA, and Charo IF. Transient Role for CD1d-Restricted Natural Killer T Cells in the Formation of Atherosclerotic Lesions. Arteriosclerosis, Thrombosis, and Vascular Biology. 2005;25(3):628-32.

32. Brennan PJ, Brigl M, and Brenner MB. Invariant natural killer T cells: an innate activation scheme linked to diverse effector functions. Nat Rev Immunol. 2013;13(2):101-17.

33. Tyznik AJ, Verma S, Wang Q, Kronenberg M, and Benedict CA. Distinct Requirements for Activation of NKT and NK Cells during Viral Infection. The Journal of Immunology. 2014;192(8):3676-85.

34. Mora S, Szklo M, Otvos JD, Greenland P, Psaty BM, Goff Jr DC, O’Leary DH, Saad MF, Tsai MY, and Sharrett AR. LDL particle subclasses, LDL particle size, and carotid atherosclerosis in the Multi-Ethnic Study of Atherosclerosis (MESA). Atherosclerosis. 2007;192(1):211-7.

35. Chung C, Oeser A, Raggi P, Solus J, Avalos I, Linton M, Fazio S, and Michael Stein C. Lipoprotein subclasses and particle size determined by nuclear magnetic resonance spectroscopy in systemic lupus erythematosus. Clin Rheumatol. 2008;27(10):1227-33.

36. Ronda N, Favari E, Borghi MO, Ingegnoli F, Gerosa M, Chighizola C, Zimetti F, Adorni MP, Bernini F, and Meroni PL. Impaired serum cholesterol efflux capacity in rheumatoid arthritis and systemic lupus erythematosus. Ann Rheum Dis. 2014;73(3):609-15.

37. Fox LM, Cox DG, Lockridge JL, Wang X, Chen X, Scharf L, Trott DL, Ndonye RM, Veerapen N, Besra GS, et al. Recognition of Lyso-Phospholipids by Human Natural Killer T Lymphocytes. PLoS Biol. 2009;7(10):e1000228. 
38. Tarim E, Yigit F, Kilicdag E, Bagis T, Demircan S, Simsek E, Haydardedeoglu B, and Yanik F. Early onset of subclinical atherosclerosis in women with gestational diabetes mellitus. Ultrasound in Obstetrics and Gynecology. 2006;27(2):177-82.

39. Feingold KR GC. Introduction to Lipids and Lipoproteins. Endotext 2015.

40. BAKER JF, MORALES M, QATANANI M, CUCCHIARA A, NACKOS E, LAZAR MA, TEFF K, and VON FELDT JM. Resistin Levels in Lupus and Associations with Disease-specific Measures, Insulin Resistance, and Coronary Calcification. The Journal of Rheumatology. 2011;38(11):2369-75.

41. Jackson WD, Weinrich TW, and Woollard KJ. Very-low and low-density lipoproteins induce neutral lipid accumulation and impair migration in monocyte subsets. Scientific Reports. 2016;6(20038.

42. Khallou-Laschet J, Varthaman A, Fornasa G, Compain C, Gaston A-T, Clement M, Dussiot M, Levillain O, Graff-Dubois S, Nicoletti A, et al. Macrophage Plasticity in Experimental Atherosclerosis. PLoS ONE. 2010;5(1):e8852.

43. Denney L, Kok WL, Cole SL, Sanderson S, McMichael AJ, and Ho L-P. Activation of Invariant NKT Cells in Early Phase of Experimental Autoimmune Encephalomyelitis Results in Differentiation of Ly6Chi Inflammatory Monocyte to M2 Macrophages and Improved Outcome. The Journal of Immunology. 2012;189(2):551-7.

44. Lynch L, Michelet X, Zhang S, Brennan PJ, Moseman A, Lester C, Besra G, Vomhof-Dekrey EE, Tighe M, Koay H-F, et al. Regulatory iNKT cells lack expression of the transcription factor PLZF and control the homeostasis of Treg cells and macrophages in adipose tissue. Nat Immunol. 2015;16(1):85-95.

45. Boß M, Kemmerer M, Brüne B, and Namgaladze D. FABP4 inhibition suppresses PPAR $\gamma$ activity and VLDL-induced foam cell formation in IL-4-polarized human macrophages. Atherosclerosis. 2015;240(2):424-30.

46. Shaikh S, Brittenden J, Lahiri R, Brown PAJ, Thies F, and Wilson HM. Macrophage Subtypes in Symptomatic Carotid Artery and Femoral Artery Plaques. European Journal of Vascular and Endovascular Surgery. 2012;44(5):491-7.

47. Stöger JL, Gijbels MJJ, van der Velden S, Manca M, van der Loos CM, Biessen EAL, Daemen MJAP, Lutgens E, and de Winther MPJ. Distribution of macrophage polarization markers in human atherosclerosis. Atherosclerosis. 2012;225(2):461-8.

48. Cho KY, Miyoshi H, Kuroda S, Yasuda H, Kamiyama K, Nakagawara J, Takigami M, Kondo T, and Atsumi T. The Phenotype of Infiltrating Macrophages Influences Arteriosclerotic Plaque Vulnerability in the Carotid Artery. Journal of Stroke and Cerebrovascular Diseases. 2013;22(7):910-8.

49. Hochberg MC. Updating the American College of Rheumatology revised criteria for the classification of systemic lupus erythematosus. Arthritis Rheum. 1997;40(9):1725.

50. A. CL. Extraction of lipids from human whole serum and lipoproteins and from rat liver tissue with methylene chloride-methanol: a comparison with extraction with chloroform: methanol. Clinica Chimica Acta. 1985;149(

51. Ala-Korpela M, Kangas A, and Soininen P. Quantitative high-throughput metabolomics: a new era in epidemiology and genetics. Genome Medicine. 2012;4(4):36.

\section{SUPPLEMENTAL REFERENCES}

1. Griffin M, Nicolaides AN, Belcaro G, and Shah E. Cardiovascular risk assessment using ultrasound: the value of arterial wall changes including the presence, severity and character of plaques. Pathophysiol Haemost Thromb. 2002;32(5-6):367-70.

2. Griffin M, Nicolaides A, Tyllis T, Georgiou N, Martin RM, Bond D, Panayiotou A, Tziakouri C, Doré CJ, and Fessas C. Carotid and femoral arterial wall changes and the prevalence of clinical cardiovascular disease. Vascular Medicine. 2009;14(3):227-32.

3. Nicolaides AN, Kakkos SK, Kyriacou E, Griffin M, Sabetai M, Thomas DJ, Tegos T, Geroulakos G, Labropoulos N, Doré CJ, et al. Asymptomatic internal carotid artery stenosis and cerebrovascular risk stratification. Journal of Vascular Surgery. 2010;52(6):1486-96.e5.

4. Kraemer S, Vaught JD, Bock C, Gold L, Katilius E, Keeney TR, Kim N, Saccomano NA, Wilcox SK, Zichi D, et al. From SOMAmer-based biomarker discovery to diagnostic and clinical applications: a SOMAmerbased, streamlined multiplex proteomic assay. PLoS One. 2011;6(10):e26332. 
5. Peralbo E, Alonso C, and Solana R. Invariant NKT and NKT-like lymphocytes: two different $\mathrm{T}$ cell subsets that are differentially affected by ageing. Exp Gerontol. 2007;42(8):703-8.

6. Kettunen J, Tukiainen T, Sarin A-P, Ortega-Alonso A, Tikkanen E, Lyytikainen L-P, Kangas AJ, Soininen $\mathrm{P}$, Wurtz P, Silander K, et al. Genome-wide association study identifies multiple loci influencing human serum metabolite levels. Nat Genet. 2012;44(3):269-76.

7. Gupta A, Kesavabhotla K, Baradaran H, Kamel H, Pandya A, Giambrone AE, Wright D, Pain KJ, Mtui EE, Suri JS, et al. Plaque Echolucency and Stroke Risk in Asymptomatic Carotid Stenosis: A Systematic Review and Meta-Analysis. Stroke. 2015;46(1):91-7. 


\section{ACKNOWLEDGMENTS}

Funding: Arthritis Research UK Career progression Fellowship to ECJ (20085), Lupus UK PhD studentship to ES, BHF PhD studentship to KW (FS/13/59/30649). Lupus UK and The Rosetrees Trust PhD studentship to SC. Statistical support from Dr Maria de Iorio, Statistical Science Department, UCL. The authors have declared that no conflict of interest exists.

\section{AUTHOR CONTRIBUTIONS}

Design of research study; ECJ, ES, IPT, RS, AN, MG, KW: Conducting experiments; ES, KW: Acquiring experimental data; ES, KW: Analyzing data, ES, SC, KW, ECJ, IPT: Patient recruitment and assessment; AR, DAI, SC: Acquisition and analysis of the vascular scanning data MG, AN and SC; Writing the manuscript; ECJ, ES, AR, SC, KW: Review of the manuscript; AR, IPT, DAI, RS, AN, MG. 


\section{FIGURE LEGENDS}

Figure 1

A
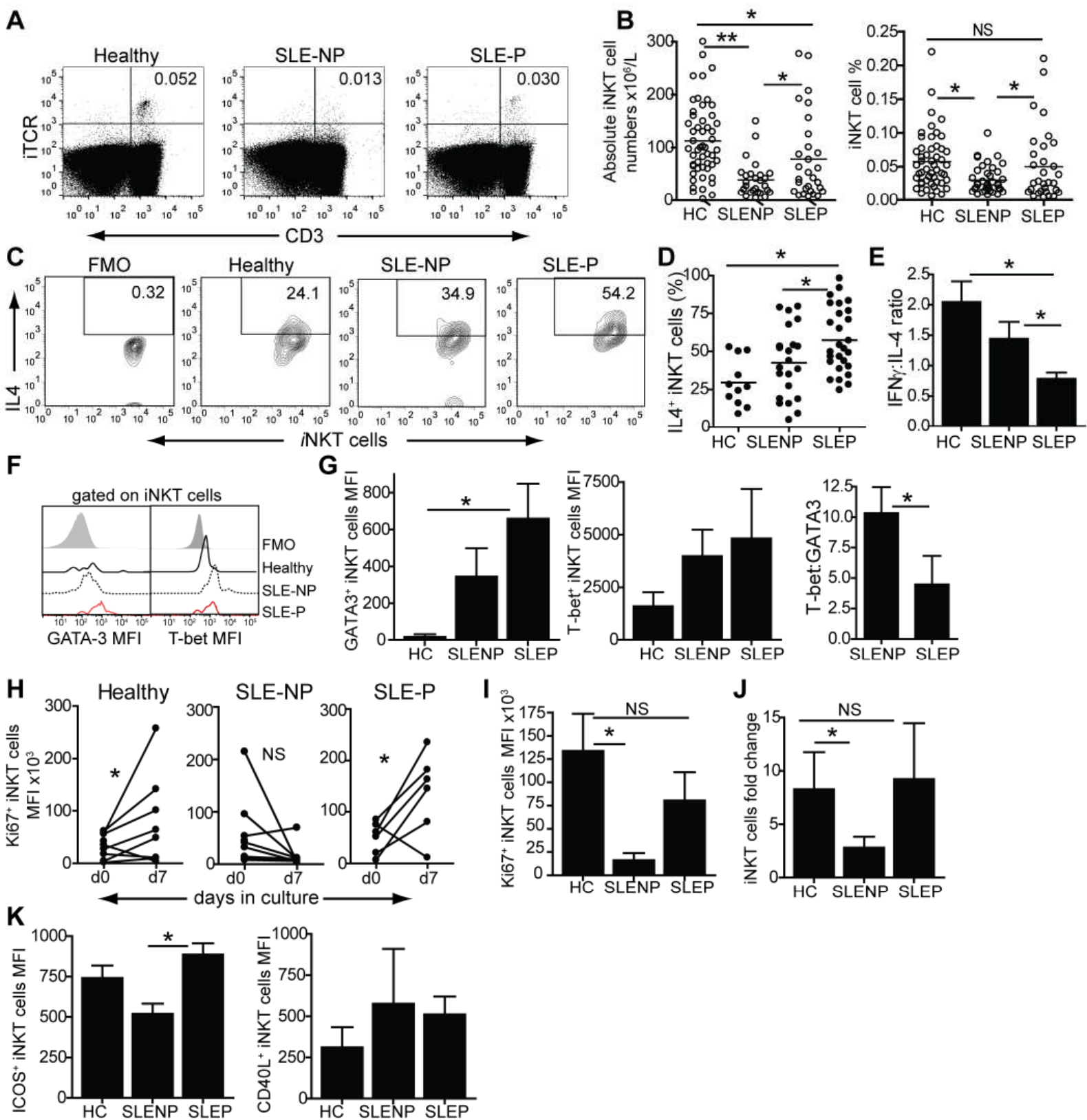

Figure 1: SLE patients with sub-clinical plaque had a distinct $i$ NKT cell phenotype. Ex vivo $i$ NKT cell frequency in PBMCs. (A) Representative flow cytometry dotplots and (B) cumulative data showing mean $i$ NKT cell absolute numbers $\left(* * \mathrm{p}=0.001 ;{ }^{*} \mathrm{p}=0.01\right)$ and percentage $(\mathrm{HC}$ vs 
SLE-NP, *p=0.01; SLE-NP vs SLE-P, *p=0.03; HC, $\mathrm{n}=50$, SLE-NP, $\mathrm{n}=35$, SLE-P, $\mathrm{n}=30$; Oneway ANOVA post-T tests).

Intracellular IL-4 expression in ex vivo iNKT cells (C) Representative dotplots and (D) cumulative data showing IL- $4^{+} i$ NKT cells (\%) and (E) ratio of $i$ NKT cells producing IFN- $\gamma$ compared to IL-4. FMO=fluorescence minus one control. (HC vs SLE-P, *p=0.01; SLE-NP vs SLE-P, ${ }^{*} \mathrm{p}=0.05 ; \mathrm{HC} \mathrm{n}=11$, SLE-NP $\mathrm{n}=21$, SLE-P=21; One-way ANOVA post-T tests).

Ex vivo $i$ NKT cells were stained intracellularly with either T-Bet or GATA-3. (F) Representative histogram and (G) cumulative data including T-bet:GATA3 ratio. (GATA3: *p=0.01, HC n=3, SLE-P n=5, SLE-NP n=5; One-way ANOVA post-T tests; T-Bet:GATA3 ratio * $\mathrm{p}=0.05$ paired $\mathrm{T}$ test).

$i$ NKT cell proliferation (Ki-67 expression) after $7 \mathrm{~d}$ culture with $\alpha$-GalCer and IL-2. (H) $i$ NKT cell Ki-67 expression at $\mathrm{d} 0$ and $7 \mathrm{~d}$ culture $\left(\mathrm{HC} * \mathrm{p}=0.01 ;\right.$ SLE-P, ${ }^{*} \mathrm{p}=0.02 ; \mathrm{HC} \mathrm{n}=5$, SLE-NP $\mathrm{n}=7$, SLE-P $\mathrm{n}=7$, paired T test). (I) $i \mathrm{NKT}$ cell Ki-67 expression mean fluorescence intensity (MFI) at d7 $(* \mathrm{p}=0.01$, HC n=6, SLE-NP n=8, SLE-P n=9, One-way ANOVA post-T test). (J) Fold change in $i \mathrm{NKT}$ cell frequency at $\mathrm{d} 7$ compared to $\mathrm{d} 0\left({ }^{*} \mathrm{p}=0.04, \mathrm{HC} \mathrm{n}=4\right.$, SLE-NP $\mathrm{n}=7$, SLE-P $\mathrm{n}=8$, One-way ANOVA post- $\mathrm{T}$ test). (K) $i$ NKT cells positive for ICOS and CD40L expression $(\%)$ at $\mathrm{d} 7\left({ }^{*} \mathrm{p}=0.01, \mathrm{HC} n=3\right.$, SLE-NP $\mathrm{n}=5$, SLE-P $\mathrm{n}=5$; One-way ANOVA post-T test $)$. NS=not significant. 
Figure 2
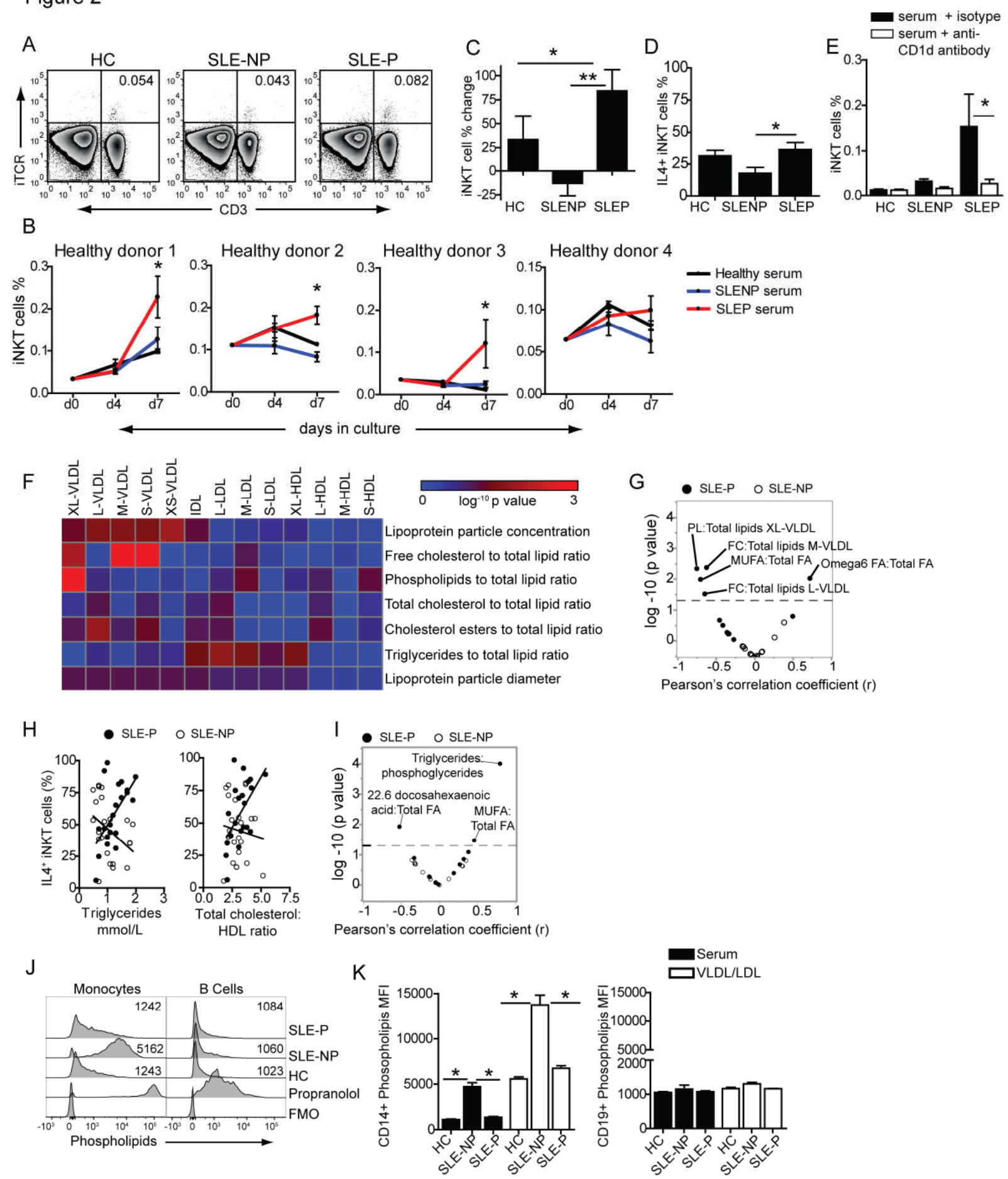

Figure 2: Dyslipidaemia was associated with altered $i$ NKT cell activation in SLE-P

compared to SLE-NP patients. PBMCs from 4 healthy donors were each cultured with $50 \%$ serum from 5 heterologous HCs, 5 SLE-P or 5 SLE-NP patients +IL-2. At d0, d4 and d7 iNKT 
cell frequency and intracellular IL-4 production were analysed by flow cytometry. (A) Representative dotplots showing $i$ NKT cell frequency at $\mathrm{d} 7$ and (B) line graphs showing individual experiments (d7 Healthy donor 1-3, HC vs SLE-P, *p=0.05; $\mathrm{n}=5$, One-Way Anova post-T test). (C) Cumulative data showing \% change in $i$ NKT cell frequency at $\mathrm{d} 7$ compared to $\mathrm{d} 0\left({ }^{*} \mathrm{p}=0.01,{ }^{*} \mathrm{p}=0.001 ; \mathrm{n}=16\right.$, One-Way Anova post-T test). (D) Cumulative data showing the percentage of $i \mathrm{NKT}$ cells producing IL-4 at $\mathrm{d} 7\left({ }^{*} \mathrm{p}=0.05 ; \mathrm{n}=10\right.$, One-Way Anova post-T test $)(\mathbf{E})$ Culture of PBMCs from a healthy donor with serum from six different healthy donors, SLE-NP and SLE-P patients \pm blocking anti-CD1d antibody or isotype control $\left({ }^{*} \mathrm{p}=0.05 ; \mathrm{n}=6\right.$, paired-T test).

Serum from 33 SLE-P and 53 SLE-NP patients were analysed by proton nuclear magnetic resonance spectroscopy for 230 serum lipid metabolites. (F) Lipoprotein size and composition between SLE-P and SLE-NP patients compared using a Students T test, converted into $\log ^{-10} \mathrm{p}$ value and plotted as a heat map. Higher $\log ^{-10} \mathrm{p}$ values (red) represent greater differences between metabolites in SLE-P compared to SLE-NP patients (Table S2, Figure S3 and S4). (G) Serum metabolite levels were correlated with $i$ NKT cell frequency for SLE-P and SLE-NP patients (Table S4). Volcano plot showing Pearson's correlation (r) vs metabolite expression (log-10 $\mathrm{p}$ values) in SLE-P and SLE-NP patients. Dotted line represents $\mathrm{p}=0.05 . \mathrm{FA}=$ fatty acid; MUFA=monounsaturated fatty acid. $(\mathbf{H})$ Correlation between $i$ NKT cell intracellular IL-4 expression and serum triglycerides (left-panel) and total cholesterol:HDL ratio (right panel) (Table S3). IL-4 vs triglycerides, SLE-P; $n=28, r=0.581, p=0.005$; SLE-NP; $n=23$ r=-0.390, $\mathrm{p}=0.07$ : IL-4 vs total cholesterol:HDL, SLE-P, $\mathrm{n}=21,0.546, \mathrm{p}=0.01$, Pearson's correlation. (I) Serum metabolite levels were correlated with $i$ NKT cell intracellular IL-4 expression for SLE-P 
and SLE-NP patients (Table S4). Volcano plot showing Pearson's correlation (r) vs metabolite expression (log-10 p values) in SLE-P and SLE-NP patients. Dotted line represents $\mathrm{p}=0.05$. HC PBMCs were cultured for 48h in RPMI/50\% PHS, isolated serum VLDL/LDL from HC, SLE-NP and SLE-P patients, or propranolol (positive control) + LipdTox $^{\mathrm{TM}}$ phospholipidosis detection reagent and analysed by flow cytometry. (J) Representative histograms showing serum culture and MFI values and $(\mathbf{K})$ cumulative data $\left({ }^{*} \mathrm{p}=0.01, \mathrm{n}=3\right.$, One-Way Anova post-T test). 
Figure 3

A

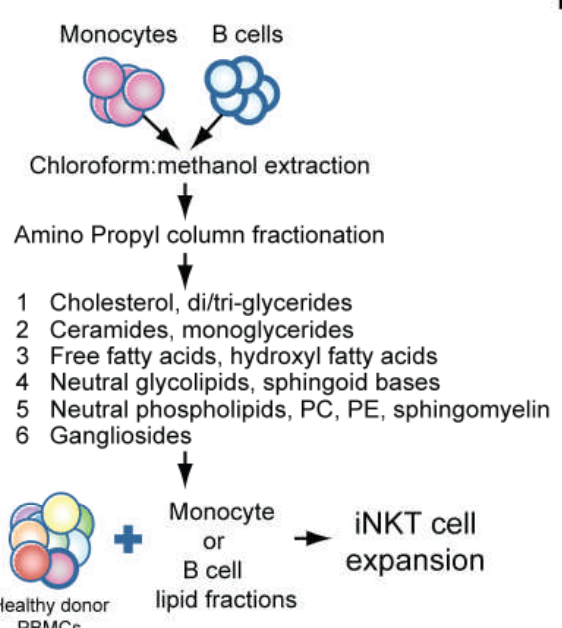

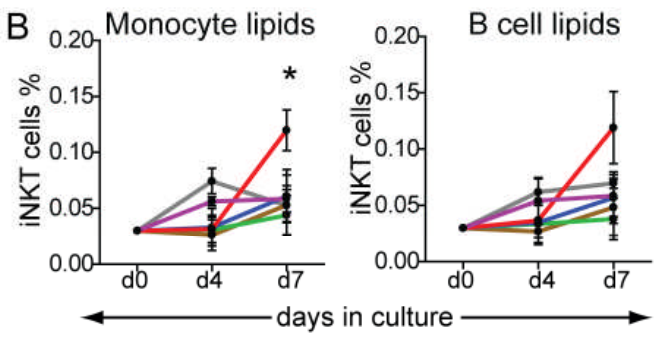

- F1: Cholesterol, di/tri glycerides

- F2: Ceremides, monoglycerides

- F3: Free fatty acids, hydroxyl fatty acids

- F4: Neutral glycolipids, sphingoid bases

- F5: Neutral phospholipids, PC, PE, sphingomyelin

- F6: Gangliosides
C
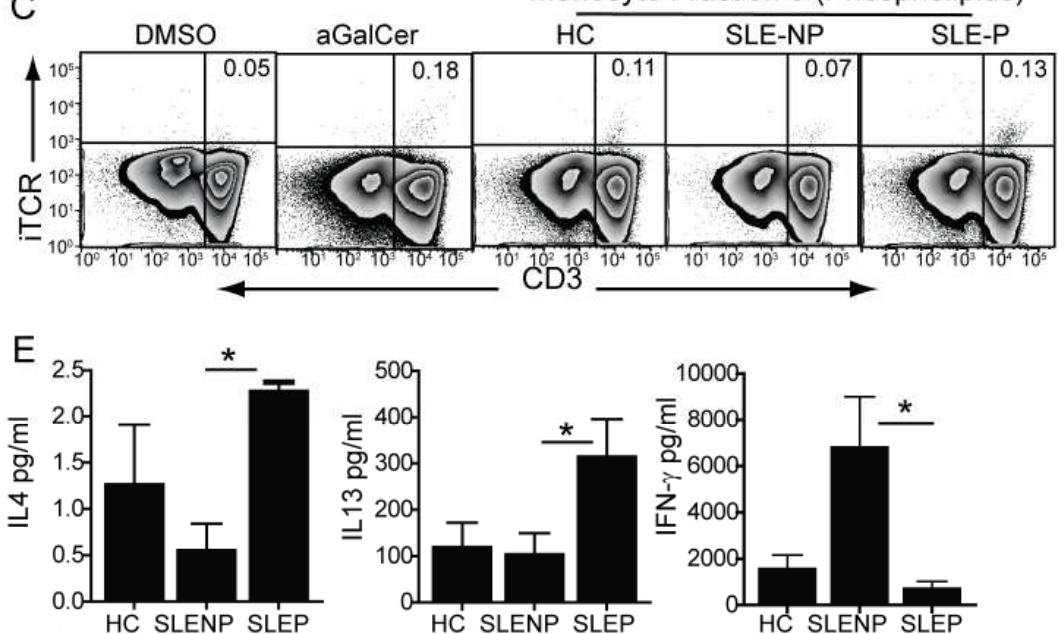

F

DMSO

+ F5 monocyte lipid + isotype
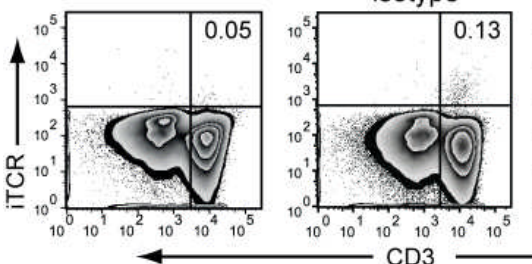

+F5 monocyte lipid

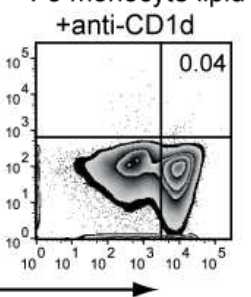

G

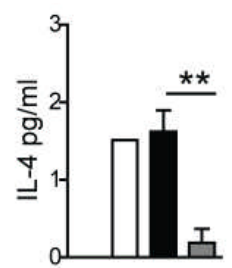

IIIm DMSO

$\alpha$-GalCer

F5 lipid + isotype $\square$ F5 lipid + anti-CD1d

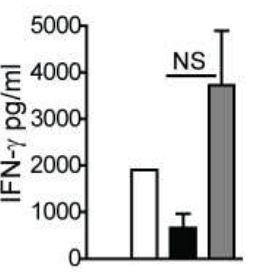


Figure 3: Altered lipid-antigen presentation by monocytes from SLE-P patients drives increased $i$ NKT cell frequency and IL4 production. (A) Experimental plan: B cell and monocyte lipids from HC, SLE-NP or SLE-P donors were isolated by chloroform: methanol extraction, and fractionated using Amino Propyl Columns (F1-F6). PBMCs from 4 HCs were stimulated with each lipid fraction +IL-2. iNKT cells were quantified by flow cytometry at d0, d4 and d7. (B) Cumulative data (F1 vs F5, p=0.05, F2 vs F5, p=0.05, F3vs F5 p=0.01, F4 vs F5 $\mathrm{p}=0.05, \mathrm{~F} 6$ vs F5*p=0.05: $\mathrm{n}=4$, One Way ANOVA, T-tests).

Fraction 5 (F5) lipids from monocytes and B cells were used to stimulate PBMCs from five HCs $+\mathrm{IL}-2$ for $7 \mathrm{ds}$. At $\mathrm{d} 7$ cell culture supernatants were collected and $i$ NKT cell frequency assessed. (C) Representative flow cytometry dotplots showing $i$ NKT cell frequency in response to monocyte derived F5 lipids compared to vehicle (DMSO). (D) Cumulative iNKT cell frequency in response to monocyte-derived and B cell-derived F5 lipids $\left({ }^{*} \mathrm{p}=0.04,{ }^{*} * \mathrm{p}=0.0001\right.$; $* * \mathrm{p}=0.006 ; \mathrm{n}=5$, One-way ANOVA post T-Tests) (E) Cell culture supernatants from $\mathrm{d} 7$ cultures with monocyte F5 lipids were assessed for IL-4, IL-13 and IFN- $-\gamma$ by CBA. Cumulative data (IL$4,{ }^{*} \mathrm{p}=0.04 ; \mathrm{IL}-13,{ }^{*} \mathrm{p}=0.05 ; \mathrm{IFN}-\mathrm{\gamma},{ }^{*} \mathrm{p}=0.05, \mathrm{n}=5$ Paired T test). The experiment described in (C-GF) was repeated \pm blocking anti-CD1d antibody or isotype control. (F) Representative flow cytometry dotplots showing iNKT cell expansion. (G) CBA data of IL-4, IL-13 and IFN-y expression in tissue culture supernatants following 7d culture with SLE-P F5 monocyte lipids \pm anti-CD1d or isotype control, compared to vehicle (DMSO) and $\alpha$ GalCer as negative and positive controls (IL-4, ${ }^{* *} \mathrm{p}=0.001 ; \mathrm{IL}-13,{ }^{* *} \mathrm{p}=0.004, \mathrm{n}=6$, Paired T test). 
Figure 4

A

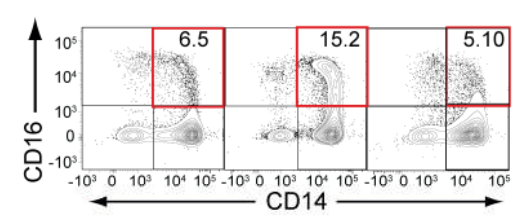

C
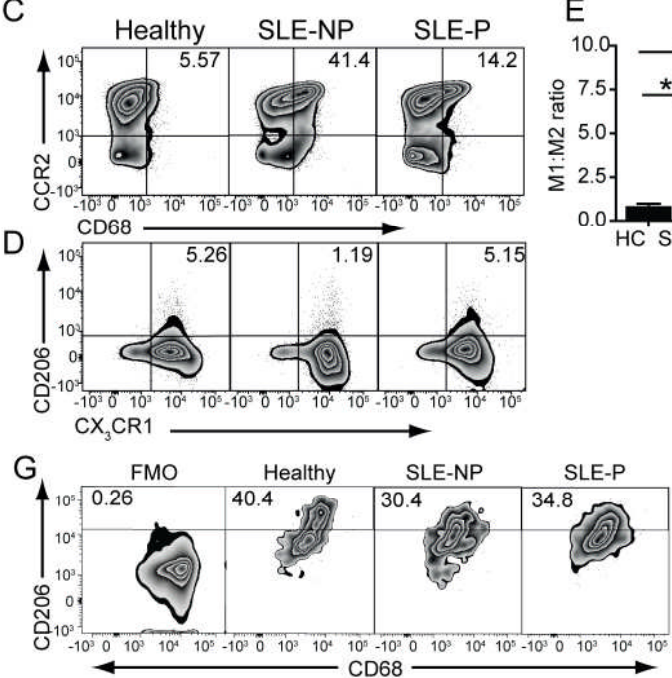

B

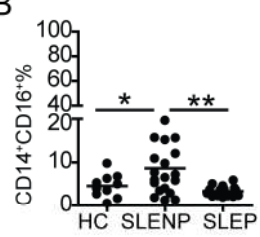

E

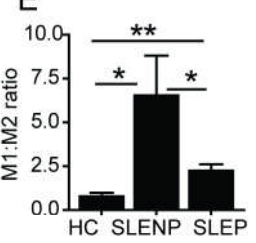

$F$

$\mathrm{H}$
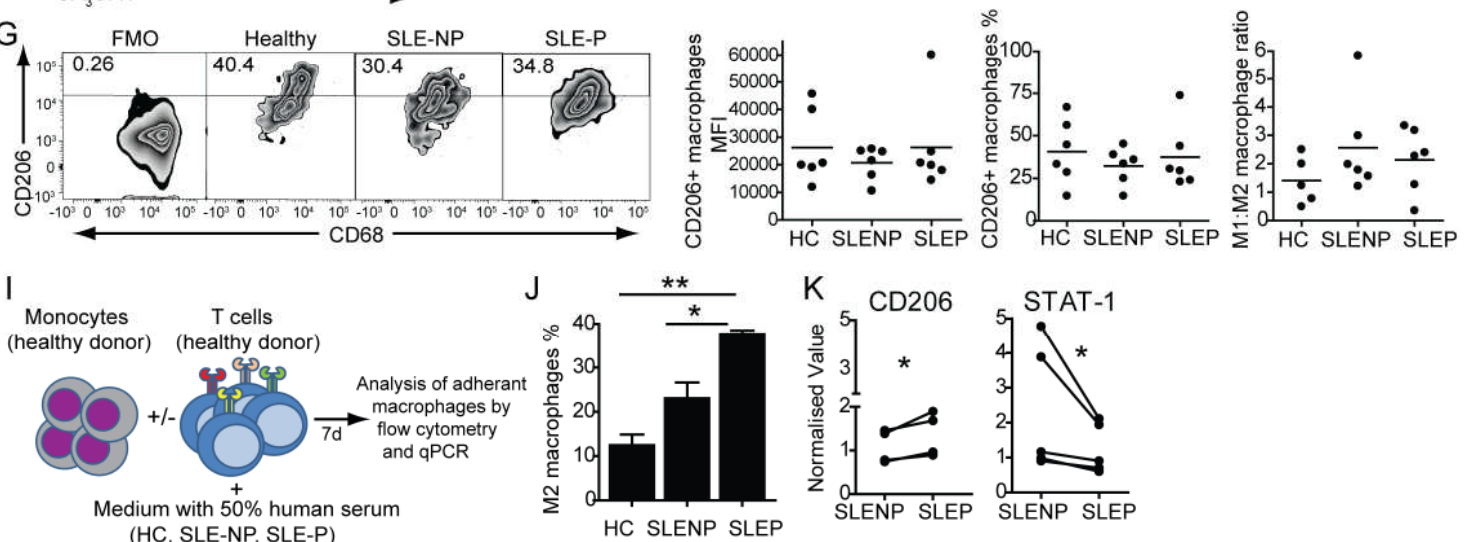

L
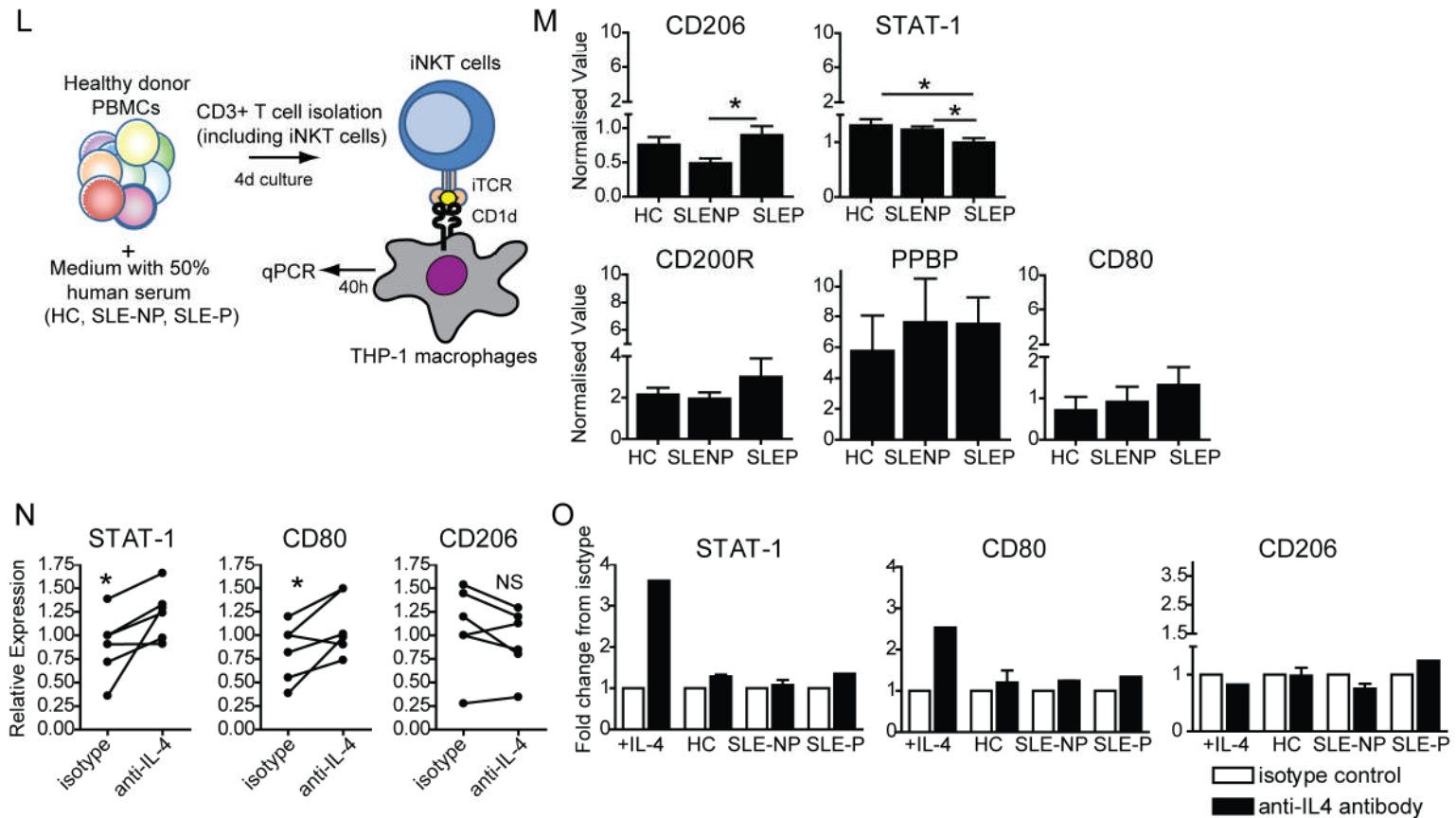
Figure 4: $i$ NKT cells from SLE patients with pre-clinical plaque support M2 macrophage differentiation

PBMCs were surface stained for monocyte subpopulations. (A) Representative flow cytometry dotplots and $(\mathbf{B})$ cumulative data for $\mathrm{CD} 14^{+} \mathrm{CD} 16^{+}$monocyte frequency $(\mathrm{HC} * \mathrm{p}=0.5$; ** $\mathrm{p}=0.01$, HCs n=10, SLE-NP n=20, SLE-P n=20; One Way ANOVA post T test). Representative plots for (C) $\mathrm{CD} 14^{+} \mathrm{CD} 68^{+} \mathrm{CCR} 2{ }^{+} \mathrm{M} 1-$ like and (D) $\mathrm{CD} 14^{+} \mathrm{CD} 206{ }^{+} \mathrm{CX}_{3} \mathrm{CR} 1{ }^{+} \mathrm{M}-2$-like monocyte populations, $(\mathbf{E})$ ratio of $\mathrm{CD} 68^{+} \mathrm{CCR} 2^{+}$to $\mathrm{CD} 206^{+} \mathrm{CX}{ }_{3} \mathrm{CR} 1^{+}$monocytes $(* \mathrm{p}=0.05 ; * * \mathrm{p}=0.004$; $\mathrm{T}$ tests) and (F) cumulative data (M1-like: ${ }^{*} \mathrm{p}=0.05$; HC vs SLE-P, ${ }^{*} \mathrm{p}=0.01$; M2-like; ${ }^{*} \mathrm{p}=0.01$; $* \mathrm{p}=0.002$, HCs $\mathrm{n}=10$, SLE-NP $\mathrm{n}=20$, SLE-P $\mathrm{n}=20$; One Way ANOVA post T test).

Monocytes from $6 \mathrm{HCs}$ were negatively isolated and cultured with RPMI containing $50 \% \mathrm{HC}$, SLE-NP or SLE-P serum for 7ds. Adherent differentiated macrophages were recovered. (G) Representative plots showing CD206 expression on $\mathrm{CD} 68^{+}$Macrophages. $\mathrm{FMO}=$ fluorescence minus one control. (H) CD206 expression on CD68 ${ }^{+}$macrophages (MFI) (left-hand panel); percentage of $\mathrm{CD}^{+} 8^{+}$macrophages positive for CD206 (centre); ratio of M1: M2 macrophages (right-hand panel). (I) Experimental plan: Purified monocytes (10\%/well) and T cells (7.5x10 $/$ well) from HCs were co-cultured with 50\% serum from 6 SLE-NP, 6 SLE-P patients and $6 \mathrm{HCs}$ for $7 \mathrm{ds}$. At d7 adherent differentiated macrophages were recovered. (J) Cumulative flow cytometry data showing frequency of M2-polarised macrophages $\left(\mathrm{CD} 68^{+} \mathrm{CD} 206^{+}\right)$ $(*=\mathrm{p}=0.008 ; * \mathrm{p}=0.015, \mathrm{n}=3$ One Way ANOVA post paired T-test $)$ and $(\mathbf{K})$ RNA was analyzed for CD206 and STAT-1 gene expression by qPCR (CD206, *p=0.050; STAT-1, *p=0.049, n=4 paired $\mathrm{T}$ test).

(L) Experimental plan: PBMC from 2 HCs were cultured with 50\% serum from 3 different HCs, 3 SLE-NP and 3 SLE-P patients for $7 \mathrm{ds}$ to induce $i$ NKT cell differentiation. Isolated $\mathrm{CD}^{+} \mathrm{T}$ 
cells (including iNKT cells) were co-cultured with differentiated THP-1 human macrophage cell line for 40hs. Macrophages were analyzed for expression of M1 and M2- associated genes by qPCR. (M) Cumulative data showing M2 (CD206 and CD200R) and M1 (STAT-1, PPBP, CD80) gene expression normalised to the level of cyclophilin (45) (CD206, *p=0.049; STAT-1, HC vs SLE-P, ${ }^{*} \mathrm{p}=0.011$, SLE-NP vs SLE-P, ${ }^{*} \mathrm{p}=0.049, \mathrm{n}=4$, One Way Anova and post $\mathrm{T}$ test). Healthy donor PBMCs ( $\mathrm{n}=2$ ) were cultured for 7ds with PHS from 5 HCs, 5 SLE-NP and 5 SLEP patients or IL-4 \pm anti-IL4 blocking antibody or isotype control. RNA from adherent macrophages was analyzed by qPCR. (N) Combined cumulative data for STAT-1, CD80 and CD206 expression, (STAT-1, ${ }^{*} \mathrm{p}=0.050, \mathrm{CD} 80,{ }^{*} \mathrm{p}=0.039 ; \mathrm{n}=6$, Paired T tests) and $(\mathbf{O})$ fold change gene expression compared to isotype (isotype=1) for macrophages cultured in HC, SLENP and SLE-P serum. 
A

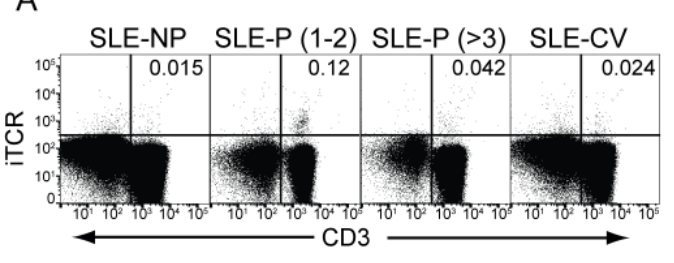

B
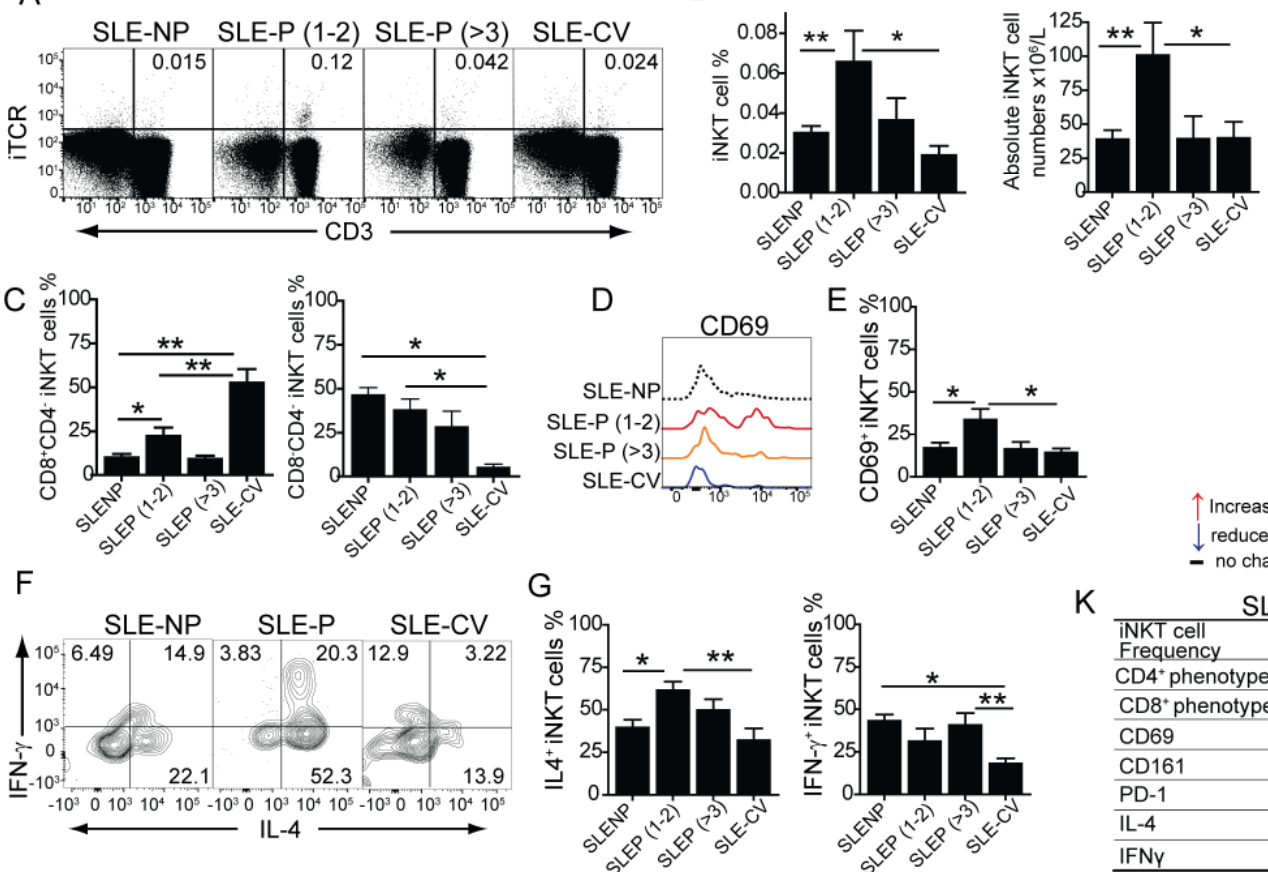

$\uparrow$ Increased compared to healthy donors

$\downarrow$ reduced compared to healthy donors

$\mathrm{K}$

SLE-NP SLE-P SLE-CV

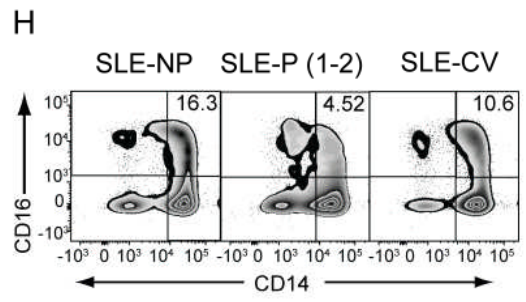

I

$\mathrm{J}$
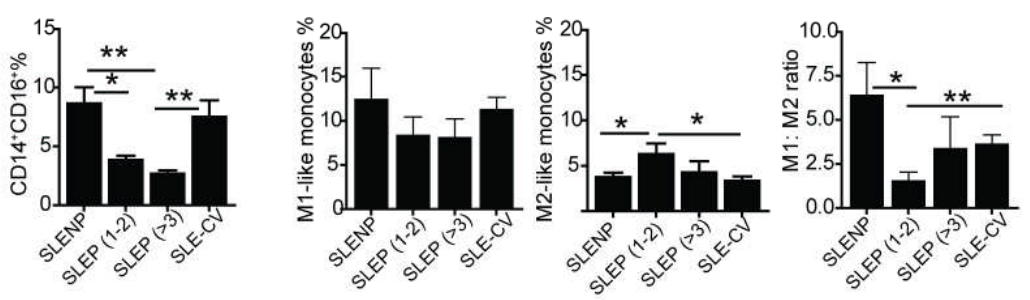

Figure 5: $i$ NKT cells from SLE patients with clinical cardiovascular disease were anergic and associated with pro-inflammatory monocytes.

Ex vivo $i$ NKT cell frequency and phenotype in SLE-NP, SLE-P patients (stratified according to number of plaque sites; 1-2 and >3 plaque sites) and SLE patients who had previously suffered a cardiovascular event (SLE-CV), Table S5. (A) Representative dot plots and (B) cumulative data showing $i$ NKT cell $\%$ and absolute number $\left(* * \mathrm{p}=0.01 ;{ }^{*} \mathrm{p}=0.05\right.$; SLE-NP $\mathrm{n}=46$, SLE-P(1-2) $\mathrm{n}=15$, SLE-P( $>3) \mathrm{n}=10$, SLE-CV $\mathrm{n}=9$; One way ANOVA post-T test) $(\mathbf{C})$ frequency of $i \mathrm{NKT}$ cell CD8+ $\left({ }^{*} \mathrm{p}=0.05 ;{ }^{* *} \mathrm{p}=0.001\right)$ and $\mathrm{CD} 8{ }^{-} \mathrm{CD} 4^{-}$subsets $\left({ }^{*} \mathrm{p}=0.01\right.$; SLE-NP $\mathrm{n}=18$, SLE-P $(1-2)$ 
$\mathrm{n}=10$, SLE-P(>3) n=10, SLE-CV n=5; One way ANOVA post-T test) (D) Representative histograms and $(\mathbf{E})$ cumulative data showing CD69 ${ }^{+} i$ KKT cells $(\%)(* \mathrm{p}=0.05$; SLE-NP $\mathrm{n}=32$, SLE-P(1-2) n=14, SLE-P(>3) n=10, SLE-CV n=8, One way ANOVA post-T test). (F) Representative dot plots and (G) cumulative data showing frequency of IFN- $\gamma^{+}$and IL- $4^{+} i \mathrm{NKT}$

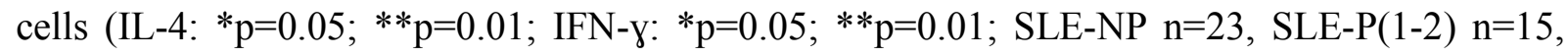
SLE-P(>3) n=11, SLE-CV n=5, One way ANOVA post-T test).

Analysis of monocyte subsets in ex vivo PBMCs. (H) Representative dot plots and (I) cumulative data for $\mathrm{CD} 14^{+} \mathrm{CD} 16^{+}$intermediate monocytes $(\%)(* \mathrm{p}=0.03 ; * * \mathrm{p}=0.01 ; 20$ SLE-NP $\mathrm{n}=20,17$ SLE-P(1-2) n=10, SLE-P(>3) n=7, SLE-CV n=8; one way ANOVA post-T-test) (J) Cumulative data for M1-like $\left(\mathrm{CD} 68^{+} \mathrm{CCR} 2^{+}\right)$monocytes, M2-like $\left(\mathrm{CD} 206^{+} \mathrm{CX}_{3} \mathrm{CR} 1^{+}\right)$monocytes $\left({ }^{*} \mathrm{p}=0.05\right)$ and M1:M2 ratio $\left(* \mathrm{p}=0.04\right.$; $*{ }^{*} \mathrm{p}=0.008$, SLE-NP $\mathrm{n}=14$, SLE-P(1-2) $\mathrm{n}=10$, SLE-P(>3) n=4, SLE$\mathrm{CV} \mathrm{n}=8$; one way ANOVA post-T-test). (K) Summary of $i$ NKT cell heterogeneity in SLE-NP, SLE-P and SLE-CV patients relative to HCs. 
Figure 6

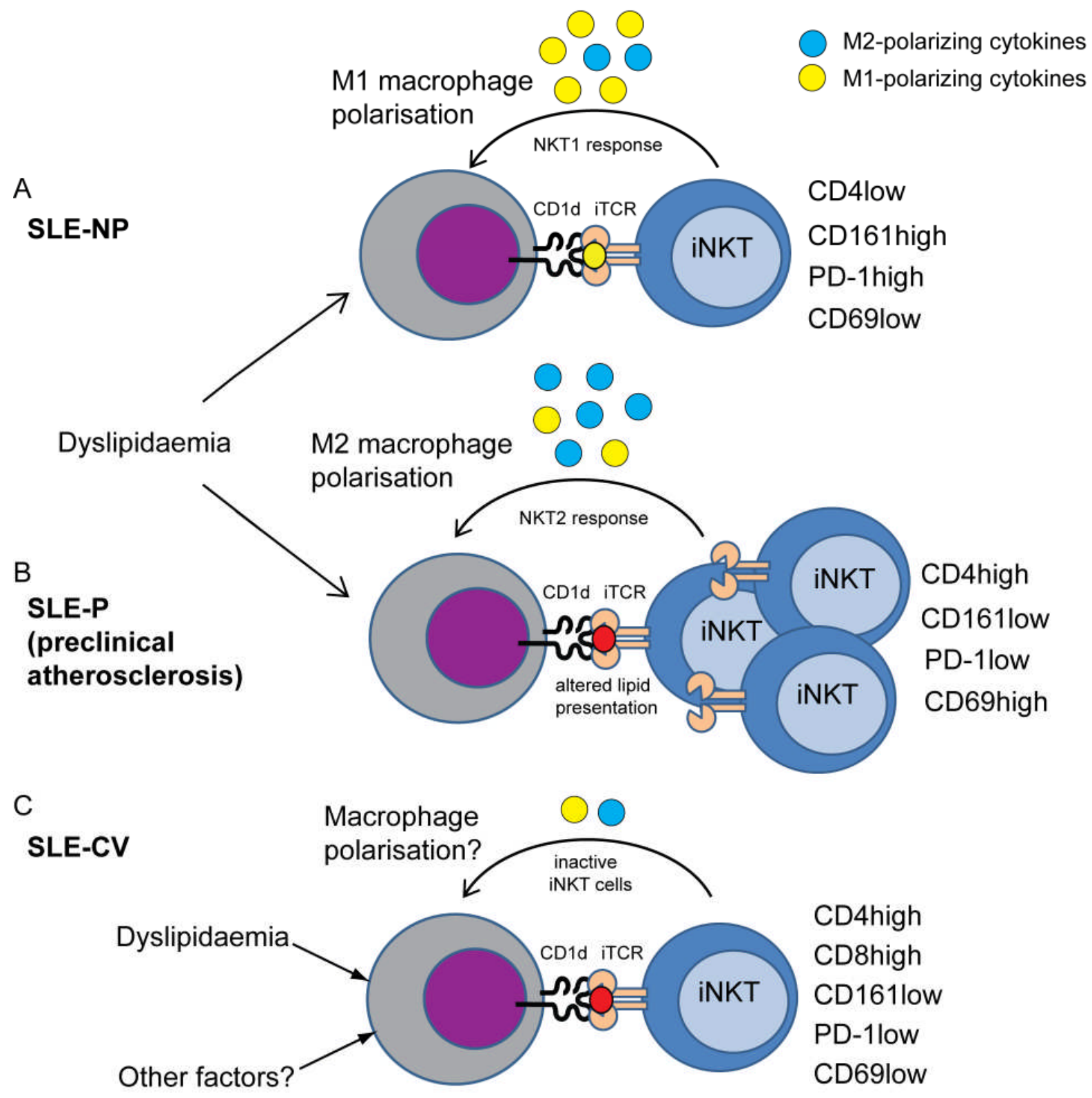

Figure 6: Proposed mechanism of $i$ NKT cell activation in SLE patients with early

atherosclerosis. Dyslipidaemia could contribute to an initial protective $i$ NKT cell response in SLE-P patients, mediated by M2-associated cytokines (including IL-4 and IL-13) and activation of M2 macrophages. (A) In SLE-NP patients: CD1d-lipid presentation induced $i$ NKT cells 
characterized by reduced frequency, CD $4^{\text {low }}, \mathrm{CD} 69^{\text {low }}, \mathrm{CD} 161^{\text {high }}, \mathrm{PD}-1^{\text {high }}$ and low IL-4 production, supporting inflammatory M1-macrophage polarization. (B) In SLE-P patients: altered presentation of phospholipids induced $i$ NKT cells characterized by increased $i$ NKT cell frequency, CD4 $4^{\text {high }}, \mathrm{CD} 69^{\text {high }}, \mathrm{CD} 16^{\text {low }}, \mathrm{PD}-1^{\text {low }}$ and elevated IL-4 production, potentially supporting M2-macrophage polarization. (C) In SLE-CV patients: continued activation could overwhelm the protective $i$ NKT cell response resulting in an unresponsive phenotype characterized by reduced frequency, CD $8^{\text {high }}, \mathrm{CD} 161^{\text {low }}, \mathrm{PD}-1^{\text {low }}$ and CD69 $9^{\text {low }}$ and reduced IFN $\gamma$ and IL-4 production and a subsequent failure to induce M2 macrophage polarization. 